\title{
SWARA-TOPSIS YÖNTEMİ İLE EN UYGUN YENİLENEBİLİR ENERJİ KAYNAĞININ BELİRLENMESİ
}

\author{
Onur DERSE ${ }^{1}$, Emel YONTAR ${ }^{*}$ \\ 1Tarsus Üniversitesi, Meslek Yüksekokulu, Yönetim ve Organizasyon Bölümü, Mersin \\ ORCID No : https://orcid.org/0000-0002-4528-1999 \\ ${ }^{2}$ Tarsus Üniversitesi, Mühendislik Fakültesi, Endüstri Mühendisliği Bölümü, Mersin \\ ORCID No : https://orcid.org/0000-0001-7800-2960
}

\begin{tabular}{l}
\hline Anahtar Kelimeler \\
\hline Yenilenebilir enerji kaynakları, \\
Cok Kriterli Karar Verme \\
Tekniği, \\
TOPSIS, \\
SWARA, \\
En uygun enerji seçimi.
\end{tabular}

En uygun enerji seçimi.

Öz

Yenilenebilir enerji kaynaklarına olan ihtiyaç ve talep her geçen gün artmaktadır. Dünyada nüfus sayısııın hızla artmasıyla birlikte hem tüketimi azaltmak hem de çevre zararını ortadan kaldırmak için yenilenebilir enerji kaynakları kullanılmaya başlanmıştır. Doğru yerde doğru yenilenebilir enerji kaynağı seçimi yapılarak yenilenebilir enerji kaynaklarından elde edilen faydalar artırlabilmektedir. Ancak bu seçim aşamasında ele alınması gereken çok fazla ve farklı kriterler ortaya çıkmaktadır. Bu çalışmada Çok Kriterli Karar Verme Tekniklerinden SWARA ile entegre TOPSIS yöntemi kullanılarak en uygun yenilenebilir enerji kaynağının seçimi ele alınmaktadır. Çalışmada, yenilenebilir enerji kaynakları olarak; rüzgâr enerjisi, güneş enerjisi, biyokütle enerjisi, hidrojen enerjisi, dalga enerjisi, hidroelektrik enerjisi ve jeotermal enerji incelenmektedir. Bu kaynakların karşılaştırılması için değerlendirme kriterleri olarak; maliyet, verimlilik, iș imkânı, elde edilebilirlik miktarı, devlet teșvikleri, sosyal kabul edilebilirlik, teknolojik olgunluk, hizmet ömrü, arıza / kaza riskinin düşüklügü, arazi ihtiyacı kriterleri dikkate alınmaktadır. Karşılaştırmalı analizlerde dikkate alınarak çalışmanın sonucunda Türkiye'de yenilenebilir enerji kaynaklarından hidroelektrik enerji santralinin kurulması gerektiği ilk sırada görülmektedir. Bu enerji kaynağını sırasıyla biyokütle enerjisi, jeotermal enerji, hidrojen enerjisi, güneș enerjisi, rüzgâr enerjisi ve dalga enerjisi takip etmektedir.

\section{DETERMINATION OF THE MOST APPROPRIATE RENEWABLE ENERGY SOURCE BY}

$$
\text { SWARA-TOPSIS METHOD }
$$

\begin{tabular}{l}
\hline Keywords \\
\hline Renewable energy sources, \\
Multi Criteria Decision Making \\
Technique, \\
TOPSIS, \\
SWARA, \\
Optimum energy choice.
\end{tabular}

\begin{abstract}
The need and demand for renewable energy sources are increasing day by day. With the rapid increase in the population in the world, renewable energy sources have been used to both reduce consumption and eliminate environmental damage. The benefits obtained from renewable energy sources can be increased by choosing the right renewable energy source in the right place. However, there are many and different criteria that need to be addressed at this election stage. In this study, the selection of the most suitable renewable energy source is discussed by using the TOPSIS method integrated with SWARA which is one of the Multiple Criteria Decision-Making Techniques. In the study, renewable energy sources; wind energy, biomass energy, solar energy, hydrogen energy, wave energy, hydroelectric, and geothermal are examined. As evaluation criteria for comparison of these resources; cost, efficiency, job opportunities, availability, government incentives, social acceptability, technological maturity, service life, low risk of failure/accident, land requirement criteria are taken into consideration. The results of the study with comparative analysis indicate that more priority in accordance with Turkey's hydroelectric plants. This energy source is followed by biomass energy, geothermal energy, hydrogen energy, solar energy, wind energy, and wave energy respectively.
\end{abstract}

\begin{tabular}{llll} 
Araştırma Makalesi & & Research Article & \\
Başvuru Tarihi & $: 21.09 .2020$ & Submission Date & $: 21.09 .2020$ \\
Kabul Tarihi & $: 19.11 .2020$ & Accepted Date & $: 19.11 .2020$ \\
\hline
\end{tabular}

*Sorumlu yazar; e-posta : eyontar@tarsus.edu.tr 


\section{Giriş}

Dünya nüfusunun hızlı bir șekilde artmasıyla birlikte enerji ihtiyacı giderek artmaktadır (Hepbaşlı ve Özgener, 2004; Uygurtürk ve Korkmaz, 2012). Bu ihtiyaç artışı insanların yenilenebilir enerji kaynaklarına ihtiyacını ve ilgisini de arttırmaktadır (Illkiliç, 2012). Yenilenebilir enerji kaynakları, rüzgar enerjisi, güneș enerjisi, biyokütle enerjisi, hidrojen enerjisi, dalga enerjisi, hidroelektrik enerjisi, gelgit enerjisi ve jeotermal enerji olarak sıralanabilir. Güneș enerjisi en temel yenilenebilir enerji kaynaklarından biridir ve gücünü güneșin oluşturduğu ısıdan alır. Rüzgar enerjisi hava basınç farklılıklarından, jeotermal enerji yer altı sıcaklıklarından, hidroelektirik enerjisi suyun akma veya düşme gücünden, dalga enerjisi denizlerde ve okyanuslarda oluşan su akıntılarından, gelgit enerjisi okyanuslarda oluşan gelgit olayından genel olarak gücünü almaktadır. Biyokütle enerjisi organik atıklardan ve hidrojen enerjisi hidrojen elementinin saf olarak ayrıştırılması ve kullanılmasından gücünü almaktadır. Bu enerji kaynaklarının kullanılması çevreye verilen zararlı etkinin azaltılmasına, ithalat bağımlılığının düşmesine ve daha birçok olumlu etkiye neden olmaktadır.

Yenilenebilir enerji kaynaklarına artan ilgi sonucunda açılan birçok tesis günümüzde kullanılmaktadır. Bu tesisler için ele alınması gereken en önemli problemlerin bașında hangi yenilenebilir enerji kaynağının kullanılması ve bu kullanıma karar vermek için hangi kriterlerin gözden geçirildiğine karar verilmesidir.

Seçim kararı değerlendirme süreci çok sayıda kriteri içerdiğinden ve birbirleriyle çakışan bu kriterler arasından bir seçim yapmak gerekli olduğundan, bu karar verme problemleri karmaşık problemlerdir (Ömürbek, Üstündag ve Helvacioglu 2013; Bülbül ve Köse, 2011). Karar verme problemi, genellikle seçilecek alternatifler içerisinden belirli bir amaç doğrultusunda ve belirli kriterlere dayanarak en uygun alternatifi ya da alternatifleri seçme süreci olarak ele alınır. Süreç, karar vericinin mevcut seçenekler arasından bir seçim, sıralama ya da sınıflandırma yapması şeklinde sonuçlanabilir (Geyik, Tosun, Ünlüsoy, Hamurcu ve Eren, 2016). Bu aşamada uygun karar vermek için, Çok Kriterli Karar Verme (ÇKKV) yöntemleri kullanılmaktadır (Geyik ve diğ., 2016; Akyüz ve Soba 2013).

ÇKKV yöntemleri, birden çok kriterli alternatiflerin sıralanmasında oldukça geniş bir kullanım alanına sahiptir (Özdemir ve Seçme, 2009) ve birçok alanda başarılı bir şekilde uygulanmıştır. (Eleren ve Karagül, 2008). Bu, karar alacak kişilerin çok kriterli farklı sorunlarla karşılaşmaları ve bu sorunlara en kısa süre içinde çözüm bulmak zorunda olmaları nedeniyle genel olarak uygulanmaktadır. ÇKKV yöntemleri birden fazla kriterle klyaslanan alternatifler arasından en uygun olanı seçmek ve değerlendirmek için karar alıcılara destek sağlamaktadır (Yoon, 1985). ÇKKV yöntemleri birçok farklı yöntemi içinde barındırmaktadır, bu yöntemlerden bazıları Technique for Order of Preference by Similarity to Ideal Solution (TOPSIS), ELimination Et Choice Translating REality (ELECTRE), Analytic Hierarchy Process (AHP), Stepwise Weight Assessment Ratio Analysis (SWARA) vb yöntemlerdir (Eleren ve Karagül, 2008). Madlener, Antunes ve Dias (2009), Rupf, Bahri, De Boer ve McHenry (2016), Martinez, Mustapha, Campbell ve Bouragba (2016), Wiguna, Sarno ve Ariyani (2016) ve Laska (2017), ÇKKV yöntemlerini kullanarak yenilenebilir enerji ile ilgili çalıșmalar yürütmüşlerdir.

$\mathrm{Bu}$ çalışmada SWARA ve TOPSIS yöntemlerinden oluşan iki aşamalı bir metot önerilmiștir. SWARA yöntemi ile ilgili literatürü incelerken, birçok farklı alanda uygulama bulmak mümkündür. Zolfani, Aghdaie, Derakhti, Zavadskas ve Varzandeh (2013) ürünlerin tasarımında, Aghdaie, Zolfani ve Zavadskas (2013) makine tezgahı seçiminde, Keršuliene, Zavadskas ve Turskis (2010) rasyonel uyuşmazlık çözüm yöntemi seçiminde, Zolfani ve Saparauskas (2013) enerji sürdürülebilirliği göstergelerinin önceliklendirilmesinde, Vafaeipour, Zolfani, Varzandeh, Derakhti ve Eshkalag, (2014) güneş enerjisi santrallerinin kurulacağı bölgenin seçiminde, Volvačiovas (2014) kamu binalarını geliştirme stratejisinde, Zolfani ve Banihashemi (2014); Karabasevic, Stanujkić ve Urošević (2015) ve Karabasevic, Zavadskas, Turskis ve Stanujkic (2016) personel seçiminde, Dehnavi, Aghdam, Pradhan ve Varzandeh (2015) bölgesel heyelan tehlikesinin tespitinde ve Mavi, Goh ve Zarbakhshnia (2017) sürdürülebilir üçüncü parti lojistik sağlayıcı seçiminde SWARA yöntemini ele almaktadır.

TOPSIS yöntemiyle yapılan çeșitli uygulamalar incelendiğinde; Huang ve Huang (2012) elektrik güç kaynağı bürolarının performansının değerlendirilmesinde, Wang ve Lee (2009) tedarikçi seçiminde, Bottani ve Rizzi (2006); Bianchini (2018) en uygun lojistik hizmet sağlayıcısı seçiminde, Pal ve Choudhury (2009); Mukherjee ve Nath (2005); Demireli (2010) bankanın performansın 
değerlendirilmesinde, Ertuğrul ve Özçil (2014) klima seçiminde, Xue, Zhao ve Guo (2008) hizmet kalitesinin değerlendirilmesinde, Aslan, Yıldız ve Uysal (2015) afet yeri için en uygun yerin seçiminde, Feng ve Wang (2001) yolcu taşıma sektör performansının değerlendirilmesinde, Hsu, Tsai ve Wu (2009) havayolu firma seçiminde bu yöntemin kullanıldı̆̆ kullanılarak gerçekleștirilen yenilenebilir enerji kaynağı çalışmaları da mevcuttur. Trappey, Trappey, Wang, Ou ve Li, (2015) çalışmalarında, Türkiye'de yenilenebilir enerji kaynakları içerisinden uygun olan seçimi yapmayi ele almaktadır. Ligus ve Peternek (2018) çalışmalarında, Polonya'da nükleer enerji ile yenilenebilir enerji arasında kıyaslama yaparak, yenilenebilir enerji kullanımının daha uygun olduğunu ortaya koymaktadır. Aryanpur, Atabaki, Marzband, Siano ve Ghayoumi (2019) çalıșmalarında İran'daki bir bölgede sürdürebilirliği sağlamak için 18 farklı kriteri klyaslamaktadır. Solangi, Tan, Mirjat, Valasai, Khan ve Ikram, (2019) çalışmalarında, Pakistan için güneş, hidroelektrik, biyokütle, rüzgar ve jeotermal enerji için sıralama oluşturmaktadır. Sonuç olarak, rüzgar enerjisini elektrik üretimi için en uygun yenilenebilir enerji kaynağı olduğu ortaya çıkmakta ve onu takiben hidroelektrik, güneș, biyokütle ve jeotermal enerji gelmektedir. $\mathrm{Bu}$ çalıșmalara ek olarak Alkan ve Albayrak, (2020) yenilenebilir enerji kaynaklarını Türkiye'deki yirmi altı bölgeye göre sıralamak ve değerlendirmek istemişlerdir. $\mathrm{Bu}$ çalışmada, değerlendirme kriterlerinin önem düzeyi ağırlıkları Bulanık Entropy yöntemi ile ölçülmüştür. Daha sonra Fuzzy COPRAS ve Fuzzy MULTIMOORA yöntemleri ile bölgeler için yenilenebilir enerji kaynakları alternatif sıralamaları elde edilmiştir. Fuzzy COPRAS sonuçlarına göre, hidroelektrik enerji kaynağı on yedi bölge için uygun yenilenebilir enerji kaynağı alternatifi olarak tanımlanmıştır. Fuzzy MULTIMOORA sonuçlarına göre hidroelektrik enerji kaynağı on sekiz bölge için birinci sırada uygun yenilenebilir enerji kaynağı alternatifi olarak belirlenmiştir. Shao, Han, Sun, Xiao, Zhang ve Zhao (2020), 2001'den 2018'e kadar yayınlanan toplam 85 makaleyi kapsayan yenilenebilir enerji yer seçimi için çok ölçütlü karar verme uygulamalarının sistematik bir literatür incelemesini yapmışlardır. $\mathrm{Bu}$ araştırmaya göre; (1) literatür araştırmaları ve uzman görüşleri en yaygın kriter seçim yöntemidir, (2) Yeniden sinıflandırma, en sık kullanılan veri normalleştirme yöntemidir (3) Analitik hiyerarşi süreci ağırlıklandırma için popülerdir (4) Alternatif değerlendirmede, coğrafi bilgi sistemleri ve ağırlıklı doğrusal kombinasyon en popüler araçlardır (5) Kriter ağırlıklarının değiștirilmesi, en yaygın olarak kullanılan sonuç doğrulama yöntemidir, olarak belirlenmiștir. Ghenai, Albawab, Bettayeb (2020), çalışmalarında çok kriterli karar verme modelinden SWARA / ARAS yöntemi kullanmışlardır. Beș sürdürülebilirlik kriteri (kaynak, çevresel, ekonomik, sosyal ve teknoloji) ve on dört alt kategori (alan, malzeme, enerji inşaatı, enerji-yakıt, CO2inşaat, C02-yakıt, sermaye-inşaat, sermaye-yakıt, teslim edilen enerji maliyeti, mevcut kurulu kapasite, büyüme oranı, kapasite faktörü, sistem verimliliği ve ömür) bu analize dahil edilmiștir. SWARA-ARAS hibrit yöntemini kullanarak (1) rüzgar enerjisi sistemleri (kara tabanlı), (2) katı oksit yakıt hücresi , (3) fosforik asit yakıt hücresi ve (4) güneş enerjisi sistemleri (poli-silikon) sıralanmıştır. Lee ve Chang (2018) dört çok ölçütlü karar verme yöntemi (WSM, VIKOR, TOPSIS ve ELECTRE) kullanarak Tayvan'da elektrik üretimi için yenilenebilir enerji kaynaklarının sıralamasının karşılaştırmalı analizini sunmuşlardır. Sıralama sonuçları, hidroliğin Tayvan'daki en iyi alternatif olduğunu, ardından güneş, rüzgar, biyokütle ve jeotermal olduğunu göstermiştir.

$\mathrm{Bu}$ çalıșmada ise, Türkiye'de genelinde kurulmak üzere en uygun yenilenebilir enerji kaynağı seçimi için ÇKKV yöntemlerinden SWARA ve TOPSIS yöntemi birlikte kullanılmaktadır. Çalışmada belirlenen kriterlerin önemi SWARA metoduyla belirlenmektedir. Belirlenen önem dereceleri ardından en uygun enerji seçimi probleminde TOPSIS yöntemi ele alınmaktadır. SWARA ile entegre TOPSIS yönteminin kullanım nedenlerinin başında karar vericilere kriter öncelikleri belirleme konusunda daha fazla firsat vermesi gelmektedir. Çalışmada, yenilenebilir enerji kaynakları olarak; rüzgar enerjisi, güneș enerjisi, biyokütle enerjisi, hidrojen enerjisi, dalga enerjisi, hidroelektrik enerjisi ve jeotermal enerji ele alınmaktadır. Ele alınan enerji kaynaklarının karşılaştırılmasında kullanılan değerlendirme kriterleri kapsamlı bir literatür taraması yapılarak bulunmuştur. 20 kriter çalışmada SWARA yöntemi ile incelenmeye alınmıștır ve elde edilen bulgulara Pareto Analizi uygulanarak 10 kriterin önem derecesi daha yüksek olduğu anlașılmıștır. Maliyet, verimlilik, iș imkânı, elde edilebilirlik miktarı, devlet teşvikleri, sosyal kabul edilebilirlik, teknolojik olgunluk, hizmet ömrü, arıza / kaza riskinin düşüklüğü, arazi ihtiyacı kriterleri kullanılarak ele alınan yenilenebilir enerji kaynakları için TOPSIS yöntemi kullanılarak çalışma 
sonucunda en uygun enerji kaynağı sıralaması belirlenmiștir.

\section{Materyal ve Metot}

Çalışma iki aşamadan oluşmaktadır. İlk aşama SWARA yöntemi ile yenilenebilir enerji kaynaklarını değerlendirmede kullanılacak kriterlerin önem düzeylerinin belirlenmesi, ikinci aşama ise ele alınan enerji kaynaklarının TOPSIS yöntemi ile değerlendirilmesi olmaktadır.

$\mathrm{Bu}$ çalışmada araştırma ve yayın etiğine uyulmuştur.

\subsection{SWARA Yöntemi}

SWARA (Step-wise Weight Assessment Ratio Analysis) yöntemi "Adım Adım Ağırlık Değerlendirme Oran Analizi" olarak bilinmektedir ve 2010 yılında Kersuliene, Zavadskas ve Turskis tarafından geliştirilmiştir. $\mathrm{Bu}$ yöntem uzman görüşlerinin kolaylıkla sürece dahil edilebileceği, basit göreli karşılaştırmanın kullanılabileceği bir yöntemdir (Alimardani, 2013). Bu yöntemde kriterlerin ağırlıklarının hesaplanmasında, öneminin belirlenmesinde uzmanların fikirleri oldukça önemlidir.

SWARA yöntemi kullanılarak kriterlerin göreceli ağırlıklarının belirlenme süreci şu adımları içermektedir (Stanujkic, Karabasevic ve Zavadskas 2015);

Adım 1: Kriterler, uzman görüşü doğrultusunda önem sırasına göre azalan düzende sıralanır. Birden fazla karar verici olduğunda genel sıralama elde etmek için, yapılan bu işlemlerin, geometrik ortalaması alınır.

Adım 2: Her bir kriterin göreceli önem düzeyi belirlenir. Bunun için $j$. kriter, $(j+1)$. kriterle kıyaslanarak $j$. kriterin $(j+1)$. kriterden ne kadar önemli olduğu belirlenir (Ruzgys, Volvačiovas, Ignatavičius ve Turskis, 2014). Bu değer $s_{j}$ (ortalama değerin karşılaştırılmalı önemi) olarak gösterilmiştir (Kersuliene ve diğ., 2010).

Adım 3: $k_{j}$ katsayısı (1)'de ki gibi belirlenir.

$k_{j}=\left\{\begin{array}{r}1, j=0 \\ s_{j}+1, j>1\end{array}\right.$

Adım 4: $q_{j}$ değiş̧keni (2)'de ki gibi hesaplanır. $q_{j}=\left\{\begin{array}{r}1, j=0 \\ \frac{\left(q_{j}-1\right)}{k_{j}}, j>1\end{array}\right.$

Adım 5: Değerlendirme kriterlerinin göreceli ağırlıkları eşitlik (3)'de yer alan formül ile belirlenir. Burada, $w_{j}, j$. kriterin göreli ağırlığını belirtir.

$w_{j}=\frac{q j}{\sum_{k=1}^{n} q k}$

\subsection{TOPSIS Yöntemi}

TOPSIS yöntemi Hwang ve Yoon (1981) tarafından geliştirilmiştir. Bu yöntem seçilen en iyi alternatifin pozitif ideal çözüme en yakın olan ve diğer yanda ise negatif ideal çözüme en uzak olan alternatife sahip olması fikrine dayanmaktadır (Gong ve Shi, 2008; Benitez, 2007; Shukla, Agarwal, Rana ve Purohit, 2017). TOPSIS, alternatiflerin tercih sirasinı sıralamak ve en uygun seçimi belirlemek için yaygın olarak kullanılan bir yöntemdir (Gong ve Shi, 2008).

TOPSIS yöntemi 6 adımdan oluşmaktadır. $\mathrm{Bu}$ adımlar bir çözüm sürecini içermektedir. Aşağıda TOPSIS yönteminin adımları ele alınmaktadır (Geyik ve diğ., 2016).

Adım 1: Karar matrisi (A) oluşturulması

Karar matrisinin satır elemanlarında değerlendirilmek ve seçim yapmak istenen alternatifler, sütunlarında ise karar vermek için kullanılacak olan değerlendirme kriterleri yer almaktadır. Karar matrisi, karar verici tarafından oluşturulan başlangıç matrisini oluşturmaktadır. Eşitlik 4'de görülen matris de $m$ alternatif ve $n$ kriterli bir başlangıç karar matrisi örneği göstermektedir.

$$
A_{i j}=\left[\begin{array}{cccc}
a_{11} & a_{12} & \ldots & a_{1 n} \\
a_{21} & a_{22} & \ldots & a_{2 n} \\
\cdot & & & \cdot \\
\cdot & & & \cdot \\
\cdot & & & \cdot \\
a_{m 1} & a_{m 2} & \ldots & a_{m n}
\end{array}\right]
$$

Adım 2: Standart karar matrisinin oluşturulması

$\mathrm{Bu}$ işlem standart karar matrisinin yanında normalize karar matrisi adımı olarak da bilinmektedir. $\mathrm{Bu}$ adımda farklı ölçekler içindeki değerlendirilen alternatiflerin aynı ölçeğe getirilerek 
karşılaștırılabilmeleri için normalizasyon ya da standardizasyon işlemi yapılmaktadır. Normalleştirme işlemi Eşitlik 5'de görüldüğü gibidir.

$$
r_{i j}=\frac{a_{i j}}{\sqrt{\sum_{k=1}^{m} a_{k j}^{2}}}
$$

Adım 3: Ağırlıklı Karar Matrisinin Oluşturulması

$\mathrm{Bu}$ adımda ağırlıkların toplamı 1 olacak şekilde değerlendirme faktörlerinin ağırlıkları belirlenir. Belirlenen bu ağırlıklar $w_{j}$ ile ifade edilmektedir. Ağırlıklar belirlendikten sonra normalize karar matrisinin her bir elemanı $\left(r_{i j}\right)$ ilgili kriterin ağırlığı $\left(w_{j}\right)$ ile çarpılır ve $V_{i j}$ matrisi oluşturulur. $V_{i j}$ matrisi Eşitlik 6'daki gibidir.

$$
V_{i j}=\left[\begin{array}{cccc}
w_{1} r_{11} & w_{2} r_{12} & \ldots & w_{n} r_{1 n} \\
w_{1} r_{21} & w_{2} r_{22} & \ldots & w_{n} r_{2 n} \\
\cdot & & & \cdot \\
\cdot & & & \cdot \\
\cdot & & & \cdot \\
w_{1} r_{m 1} & w_{2} r_{m 2} & \ldots & w_{n} r_{m n}
\end{array}\right]
$$

Adım 4: Pozitif ve Negatif İdeal Çözümlerin Oluşturulması

TOPSIS yönteminde ideal çözüme ulaşmak için Adım 3 'de oluşturulan ağırlıklandırılmış karar matrisin her sütunundaki en büyük ve en küçük değerleri seçilir. En küçük değerler Eşitlik 7'de görüldüğü gibi $A^{-}$olarak, en büyük değerler ise Eşitlik 8'de görüldüğü gibi $A^{+}$olarak kümelenmektedir. $A^{-}$, noktaları negatif ideal uzaklığı, $A^{+}$noktaları pozitif ideal uzaklığı göstermektedir.

$$
\begin{aligned}
& A^{-}=\left\{\left(\min _{\mathrm{i}} \mathrm{v}_{\mathrm{ij}} \mid j \in J\right),\left(\max _{\mathrm{i}} \mathrm{v}_{\mathrm{ij}} \mid j \in \mathrm{J}^{\prime}\right)\right\} \\
& \mathrm{A}^{+}=\left\{\left(\max _{\mathrm{i}} \mathrm{v}_{\mathrm{ij}} \mid j \in J\right),\left(\min _{\mathrm{i}} \mathrm{v}_{\mathrm{ij}} \mid j \in J^{\prime}\right)\right\}
\end{aligned}
$$

Adım 5: Uzaklık ölçülerinin hesaplanması

İdeal noktaların tanımlanmasının ardından maksimum ideal noktalara olan uzaklık değerleri
(Eşitlik 9) ve minimum ideal noktalara olan uzaklık değerleri (Eşitlik 10) aşağıdaki formüller yardımıyla hesaplanmaktadır.

$$
\begin{aligned}
\mathrm{S}_{\mathrm{i}}^{+} & =\sqrt{\sum_{\mathrm{j}=1}^{\mathrm{m}}\left(\mathrm{v}_{\mathrm{ij}}-\mathrm{v}_{\mathrm{j}}^{+}\right)^{2}} \\
\mathrm{~S}_{\mathrm{i}}^{-} & =\sqrt{\sum_{\mathrm{j}=1}^{\mathrm{m}}\left(\mathrm{v}_{\mathrm{ij}}-\mathrm{v}_{\mathrm{j}}^{-}\right)^{2}}
\end{aligned}
$$

Adım 6: İdeal çözüme göreli yakınlığın hesaplanması

Her alternatif için ideal noktaya göre yakınlık değerleri hesaplanırken pozitif ve negatif ideal noktaya göreli yakınlık değerleri kullanılmaktadır. İdeal çözüme göre yakınlık Eşitlik 11 kullanılarak hesaplanmaktadır.

$$
\mathrm{C}_{\mathrm{i}}^{*}=\frac{\mathrm{S}_{\mathrm{i}}^{-}}{\mathrm{S}_{\mathrm{i}}^{-}+\mathrm{S}_{\mathrm{i}}^{*}}
$$

$\mathrm{C}_{\mathrm{i}}^{*}=1$ ilgili karar noktasının ideal çözüme, $\mathrm{C}_{\mathrm{i}}^{*}=0$ ilgili karar noktasının negatif ideal çözüme mutlak yakınlığını göstermektedir ve Eşitlik 12'deki değerleri alır.

$$
0 \leq \mathrm{C}_{\mathrm{i}}^{*} \leq 1
$$

Son olarak ise elde edilen değerler, büyüklük sırasına göre dizilerek karar noktalarının (alternatiflerin) önem sıraları belirlenmektedir.

\section{Bulgular}

\subsection{Alternatif Yenilenebilir Enerji Kaynakları}

Günümüzde kullanılan enerji kaynakları giderek azalmaktadır. Fosil yakıtların çevreye verdiği zarar ve tekrardan kullanılamamaları, hem maliyet kayıplarına neden olmakta hem de çevreye oldukça zarar vermektedir. Bu nedenle yenilenebilir enerji kaynaklarına yönelim giderek artmaktadır. Tablo 1'de Türkiye'deki enerji kaynaklarına göre elektrik enerjisi üretimi ve payları gösterilmektedir. Çizelgeden de görüldüğü gibi yenilenebilir enerji kaynakları ve atıkların 2006-2016 yılları arasındaki \%'lik payı giderek artmaktadır. 
Tablo 1

Türkiye'deki enerji kaynaklarına göre elektrik enerjisi üretimi ve payları (TÜİK)

\begin{tabular}{ccccccc}
\hline Yıl & $\begin{array}{c}\text { Toplam } \\
(\text { GWh })\end{array}$ & $\begin{array}{c}\text { Kömür } \\
(\%)\end{array}$ & $\begin{array}{c}\text { Sivı yakıtlar } \\
(\%)\end{array}$ & $\begin{array}{c}\text { Doğal gaz } \\
(\%)\end{array}$ & $\begin{array}{c}\text { Hidrolik } \\
(\%)\end{array}$ & $\begin{array}{c}\text { Yenilenebilir } \\
\text { Enerji ve Atıklar } \\
(\%)\end{array}$ \\
\hline 2006 & 176.300 & 26,4 & 2,4 & 45,8 & 25,1 & 0,3 \\
2007 & 191.558 & 27,9 & 3,4 & 49,6 & 18,7 & 0,4 \\
2008 & 198.418 & 29,1 & 3,8 & 49,7 & 16,8 & 0,6 \\
2009 & 194.813 & 28,6 & 2,5 & 49,3 & 18,5 & 1,2 \\
2010 & 211.208 & 26,1 & 1,0 & 46,5 & 24,5 & 1,9 \\
2011 & 229.395 & 28,8 & 0,4 & 45,4 & 22,8 & 2,6 \\
2012 & 239.497 & 28,4 & 0,7 & 43,6 & 24,2 & 3,1 \\
2013 & 240.154 & 26,6 & 0,7 & 43,8 & 24,7 & 4,2 \\
2014 & 251.963 & 30,2 & 0,9 & 47,9 & 16,1 & 4,9 \\
2015 & 261.783 & 29,1 & 0,9 & 37,9 & 25,6 & 6,5 \\
2016 & 274.408 & 33,7 & 0,7 & 32,5 & 24,5 & 8,6 \\
\hline
\end{tabular}

Yenilenebilir enerji kaynaklarının tüketilen enerji kaynakları içerisindeki payının artırılması gerekmektedir. Bunun için de doğru yerde doğru yenilenebilir enerji kaynağ ${ }_{1}$ kullanılarak verim artırılmalıdır. $\mathrm{Bu}$ çalışmada yenilenebilir enerji kaynakları olarak belirlenen enerji kaynakları şöyledir:

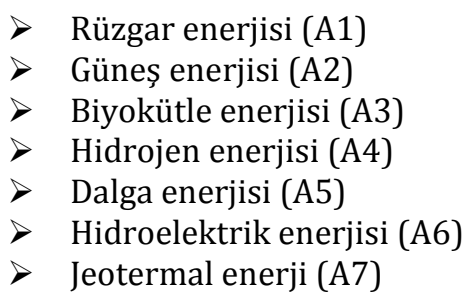

$\mathrm{Bu}$ çalışmada gelgit enerjisi alınmaması sebebi Türkiye'nin okyanusa kıyısı olmamasıdır.

\subsection{Yenilenebilir Enerji Seçiminde Kriterlerin Belirlenmesi}

Türkiye'de var olan yenilebilir enerji kaynakları (rüzgar enerjisi, güneş enerjisi, biyokütle enerjisi, hidrojen enerjisi, dalga enerjisi) seçilen araştırma kriterleri ile incelenerek bölgede kurulacak olan tesisin en uygun kaynak seçiminin bulunması amaçlanmaktadır. Çalışmada belirlenen araştırma kriterleri Çizelge 2'de yer almaktadır. Bu kriterler kapsamlı literatür taraması sonucu elde edilerek en sık rastlanan 20 adet kriter bir araya getirilmiștir. 
Tablo2

Araștırmada belirlenen değerlendirme kriterleri

\begin{tabular}{|c|c|c|c|}
\hline $\begin{array}{l}\text { Sira } \\
\text { No }\end{array}$ & Kriterler & Açıklamalar & Yazar \\
\hline 1 & Maliyet (Y1) & $\begin{array}{l}\text { Kurulumdan işletmenin işlerliği süresince ortaya } \\
\text { çlkan masrafları içerir. }\end{array}$ & $\begin{array}{l}\text { Raza, Janajreh ve Ghenai, 2014; Yücenur, } \\
\text { Çaylak, Gönül ve Postalcioğlu, 2020; Alizadeh, } \\
\text { Soltanisehat, Lund ve Zamanisabzi, 2020; } \\
\text { Özcan, Ünlüsoy ve Eren, } 2017\end{array}$ \\
\hline 2 & $\begin{array}{l}\text { Elde edilebilirlik miktarı } \\
\text { (Y2) }\end{array}$ & $\begin{array}{l}\text { Bir yenilenebilir enerji kaynağından elde edilen } \\
\text { enerjinin ne kadar yararlı ve verimli miktarda } \\
\text { olabileceğini gösterir. }\end{array}$ & \\
\hline 3 & Gürültü (Y3) & $\begin{array}{l}\text { Bölgede elektrik santrallerinin kurulması } \\
\text { nedeniyle gürültü kirliliği olasılığını ifade eder. }\end{array}$ & Solangi ve diğ. 2019; Zheng ve Wang 2020 \\
\hline 4 & Arazi ihtiyacı (Y4) & $\begin{array}{l}\text { Santral yatırım kararının verilmesinde, toplam } \\
\text { alan kullanımı ve birim } \text { m²ye enerji miktarı önemli }^{2} \\
\text { bir kriterdir. }\end{array}$ & $\begin{array}{l}\text { Beccali, Cellura ve Mistretta, 2003; Rani, } \\
\text { Mishra, Pardasani, Mardani, Liao ve } \\
\text { Streimikiene, } 2019\end{array}$ \\
\hline 5 & İş imkanı (Y5) & $\begin{array}{l}\text { Yenilenebilir enerji teknolojisinin yaşam döngüsü } \\
\text { boyunca her aşamada oluşan potansiyel işleri } \\
\text { dikkate almaktadır. }\end{array}$ & $\begin{array}{l}\text { Kaya ve Kahraman, 2010; Amer ve Daim, 2011; } \\
\text { Kabak ve Dağdeviren, 2014; Şengül, Eren, } \\
\text { Shiraz, Gezder ve SSengül, 2015; Lee ve Chang, } \\
\text { 2018; Solangi ve diğ. 2019; Wang, Xu ve } \\
\text { Solangi, } 2020\end{array}$ \\
\hline 6 & Güvenilirlik (Y6) & $\begin{array}{l}\text { Bir santralin belirtilen koşullar altında temel } \\
\text { işlevleri yerine getirme kabiliyeti olarak } \\
\text { tanımlanır. }\end{array}$ & $\begin{array}{l}\text { Beccali ve diğ. 2003; Raza ve diğ. 2014; Solangi } \\
\text { ve diğ. } 2019\end{array}$ \\
\hline 7 & Sera emisyonları (Y7) & $\begin{array}{l}\text { Yenilenebilir kaynak kullanan santrallarda çevre } \\
\text { ve insan sağlığını etkilemeyecek seviyede } \\
\text { emisyonun azaltılmasını ifade eder. }\end{array}$ & $\begin{array}{l}\text { Beccali ve diğ. 2003; Lee ve Chang, 2018; } \\
\text { Sitorus ve Parada } 2020\end{array}$ \\
\hline 8 & $\begin{array}{l}\text { Arıza / Kaza Riskinin } \\
\text { Düşüklügüü (Y8) }\end{array}$ & $\begin{array}{l}\text { Enerji tesisinin arıza veya kaza riskine olasılığ } \\
\text { incelenir. }\end{array}$ & Ligus ve Peternek 2018 \\
\hline 9 & $\begin{array}{l}\text { Sosyal kabul edilebilirlik } \\
\text { (Y9) }\end{array}$ & $\begin{array}{l}\text { Santralların toplum tarafından kabul edilirlik } \\
\text { düzeyini gösterir. }\end{array}$ & $\begin{array}{l}\text { Tsoutsos, Drandaki, Frantzeskaki, Iosifidis ve } \\
\text { Kiosses, 2009; Kahraman, Kaya ve Cebi, 2009; } \\
\text { Demirtaş, 2013; Özcan ve diğ. 2017; Lee ve } \\
\text { Chang, 2018; Rani ve diğ., } 2019\end{array}$ \\
\hline 10 & $\begin{array}{l}\text { Teknolojik olgunluk } \\
\text { (Y10) }\end{array}$ & $\begin{array}{l}\text { Teknolojinin bölgesel, ulusal ve uluslararası } \\
\text { düzeylerde ne kadar yaygın olduğunu gösterir. }\end{array}$ & $\begin{array}{l}\text { Demirtaș, 2013; Ren ve Sovacool, 2015; } \\
\text { Özkale, Celik, Turkmen ve Cakmaz., } 2017\end{array}$ \\
\hline 11 & Ekolojik etki (Y11) & $\begin{array}{l}\text { Çevresel kirlilik, canlı yaşamına etki eden } \\
\text { değișiklikler vb. etkilerin bütünüdür. }\end{array}$ & Nigim ve Munier, 2004; Zheng ve Wang 2020 \\
\hline 12 & Hizmet ömrü (Y12) & $\begin{array}{l}\text { Santral kurulum ve ișletme maliyetlerinin yüksek } \\
\text { olması nedeniyle, yatırımın } \\
\text { ekonomik ömrü kârlılığı belirleyen önemli bir } \\
\text { faktördür. }\end{array}$ & Zheng ve Wang 2020 \\
\hline 13 & Verimlilik (Y13) & $\begin{array}{l}\text { Santralin çıkış enerjisinin giriș enerjisine oranı ile } \\
\text { gösterilir. }\end{array}$ & Özcan ve diğ. 2017 \\
\hline 14 & Su tüketimi (Y14) & $\begin{array}{l}\text { Yaşam döngüsü sırasında kaynağına geri } \\
\text { döndürülmeyen yüzey suyu veya yeraltı suyu gibi } \\
\text { su rezervuarından elde edilen çekilen su } \\
\text { miktarıdır. }\end{array}$ & Şahin, 2016; Sitorus ve Parada, 2020 \\
\hline 15 & Teslim süresi (Y15) & $\begin{array}{l}\text { Bir tesisin onaylanması ve kurulması için geçen } \\
\text { süredir. }\end{array}$ & Wang ve diğ. 2020 \\
\hline 16 & $\begin{array}{l}\text { Atık üretim miktarı } \\
\text { (Y16) }\end{array}$ & $\begin{array}{l}\text { Geri Kazanımı mümkün olmayan atıkların } \\
\text { miktarıdır. }\end{array}$ & Ligus ve Peternek 2018 \\
\hline 17 & $\begin{array}{l}\text { Kaynakların } \\
\text { sürdürülebilirliği ve } \\
\text { öngörülebilirliği (Y17) }\end{array}$ & $\begin{array}{l}\text { Bölgenin kaynak bakımından yoğunluğunu, } \\
\text { devamlılığını ifade eder. }\end{array}$ & Özkale ve diğ. 2017 \\
\hline 18 & $\begin{array}{l}\text { Diş çevre } \\
\text { koordinasyon (Y18) }\end{array}$ & $\begin{array}{l}\text { Yabancı firmalarca kurulacak tesisin ülkemizle } \\
\text { olan ișbirliği düzeyini ifade eder. }\end{array}$ & Zheng ve Wang 2020 \\
\hline 19 & Devlet teşvikleri (Y19) & $\begin{array}{l}\text { Hükümet yenilenebilir enerji kaynaklarının } \\
\text { kullanımı konusunda birçok teşvik vermektedir. }\end{array}$ & $\begin{array}{l}\text { Nigim ve Munier, 2004; Ren ve Sovacool, 2015; } \\
\text { Özcan ve diğ. } 2017\end{array}$ \\
\hline 20 & $\begin{array}{l}\text { Üretim ve kurulumda } \\
\text { modülerlik (Y20) }\end{array}$ & $\begin{array}{l}\text { Tesisin gerekli büyüklüklerde kurulabilir, } \\
\text { birleştirilerek büyüyebilir ve kolayca yer } \\
\text { değiștirebilirler olmasını ifade eder. }\end{array}$ & Raza ve diğ, 2014 \\
\hline
\end{tabular}




\subsubsection{SWARA Uygulama Adımları}

SWARA yöntemi dikkate alındığında, yapılması gereken ilk aşama, elde edilen 20 kriter için (Tablo 2) uzman görüşü alınması olmuştur. Yenilenebilir enerji kaynakları, sürdürülebilirlik, enerji alanında bilgi ve tecrübe sahibi 5 akademisyenin görüşü bu doğrultuda dikkate alınmıştır. Uzmanlardan (KV1, KV2, KV3, KV4, KV5) 20 kriterin, önem sirasina göre azalan düzende sıralama yapılması istenmiştir. Birden fazla karar verici olduğu için genel sıralama elde etmek için, yapılan bu işlemlerin, geometrik ortalaması alınarak Tablo 3'de olduğu gibi nihai bir sonuç elde edilmiştir.

Tablo 3

Kriterlerin karar vericiler tarafından önem sırasına göre sıralanması

\begin{tabular}{|c|c|c|c|c|c|c|c|}
\hline $\begin{array}{l}\text { Sira } \\
\text { No }\end{array}$ & Kriterler & KV1 & KV2 & KV3 & KV4 & KV5 & $\begin{array}{c}\text { Geometrik } \\
\text { ortalama }\end{array}$ \\
\hline 1 & Maliyet (Y1) & 1 & 2 & 2 & 1 & 2 & 1,516 \\
\hline 2 & Elde edilebilirlik miktarı (Y2) & 3 & 5 & 5 & 6 & 1 & 3,393 \\
\hline 3 & Gürültü (Y3) & 20 & 16 & 20 & 14 & 16 & 17,033 \\
\hline 4 & Arazi ihtiyacı (Y4) & 13 & 7 & 11 & 16 & 7 & 10,231 \\
\hline 5 & İș imkanı (Y5) & 4 & 3 & 4 & 2 & 4 & 3,288 \\
\hline 6 & Güvenilirlik (Y6) & 14 & 15 & 7 & 15 & 8 & 11,202 \\
\hline 7 & Sera emisyonları (Y7) & 19 & 14 & 19 & 17 & 17 & 17,096 \\
\hline 8 & Arıza / Kaza Riskinin Düşüklüğü (Y8) & 12 & 17 & 8 & 7 & 9 & 10,056 \\
\hline 9 & Sosyal kabul edilebilirlik (Y9) & 6 & 4 & 6 & 5 & 6 & 5,335 \\
\hline 10 & Teknolojik olgunluk (Y10) & 11 & 8 & 10 & 8 & 10 & 9,322 \\
\hline 11 & Ekolojik etki (Y11) & 10 & 18 & 12 & 18 & 18 & 14,757 \\
\hline 12 & Hizmet ömrü (Y12) & 7 & 9 & 13 & 9 & 11 & 9,589 \\
\hline 13 & Verimlilik (Y13) & 2 & 1 & 1 & 3 & 3 & 1,783 \\
\hline 14 & Su tüketimi (Y14) & 15 & 13 & 18 & 10 & 20 & 14,766 \\
\hline 15 & Teslim süresi (Y15) & 8 & 10 & 14 & 13 & 12 & 11,181 \\
\hline 16 & Atık üretim miktarı (Y16) & 17 & 19 & 17 & 19 & 19 & 18,173 \\
\hline 17 & $\begin{array}{l}\text { Kaynakların sürdürülebilirliği ve } \\
\text { öngörülebilirliği (Y17) }\end{array}$ & 16 & 11 & 9 & 11 & 14 & 11,952 \\
\hline 18 & Diş çevre ile koordinasyon (Y18) & 18 & 20 & 16 & 20 & 15 & 17,681 \\
\hline 19 & Devlet teşvikleri (Y19) & 5 & 6 & 3 & 4 & 5 & 4,478 \\
\hline 20 & Üretim ve kurulumda modülerlik (Y20) & 9 & 12 & 15 & 12 & 13 & 12,037 \\
\hline
\end{tabular}

Bir sonraki aşamada, her bir kriterin göreceli önem düzeyi belirlenir. Yani iki kriter arası klyaslama yapılması yine uzmanlarca istenmiştir. Bunun için örneğin her kriterlerin kendi arasında karşılaştırma yapılması istenmiş (\%) ve ilk sıra için maliyet (Y1) kriterinin, verimlilik (Y13) kriteri için ne kadar önemli olduğu karar vericilere sorulmuştur. Karar verici 1 (KV1); Y1'in Y13'e göre \%20 önemli olduğunu belirtmiştir. Yine KV1, verimlilik (Y13) ve iş imkanı (Y5) kriterlerini klyaslamış ve Y5'in Y13'den \%30 daha önemli olduğunu belirtmiştir. Bu değer sj (ortalama değerin karşılaştırılmalı önemi) olarak gösterilmiştir. Her kriter bir üstündeki kriterle klyaslama yapılarak, önem dereceleri belirlenmiștir ve Tablo 4'de tek bir tablo halinde gösterilmiştir. 
Tablo 4

Kriterlerin karar vericiler tarafından belirlenen ortalama değerin karşılaştırılmalı önemi

\begin{tabular}{|c|c|c|c|c|c|c|}
\hline Kriterler & $\begin{array}{c}\text { Karar Vericilerin Önem } \\
\text { Sirası } \\
\text { (Geometrik Ortalama) }\end{array}$ & $\begin{array}{r}\mathrm{KV} 1 \\
\left(s_{j}\right)\end{array}$ & $\begin{array}{r}\mathrm{KV} 2 \\
\left(s_{j}\right)\end{array}$ & $\begin{array}{r}\mathrm{KV} 3 \\
\left(s_{j}\right)\end{array}$ & $\begin{array}{r}\mathrm{KV} 4 \\
\left(s_{j}\right)\end{array}$ & $\begin{array}{r}\mathrm{KV} 5 \\
\left(s_{j}\right)\end{array}$ \\
\hline Maliyet (Y1) & 1,516 & - & - & - & - & - \\
\hline Verimlilik (Y13) & 1,783 & 0,2 & 0,05 & 0,25 & 0,5 & 0,2 \\
\hline İş imkanı (Y5) & 3,288 & 0,3 & 0,5 & 0,4 & 0,5 & 0,2 \\
\hline Elde edilebilirlik miktarı (Y2) & 3,393 & 0,05 & 0,1 & 0,3 & 0,2 & 0,05 \\
\hline Devlet teşvikleri (Y19) & 4,478 & 0,05 & 0,15 & 0,2 & 0,4 & 0,5 \\
\hline Sosyal kabul edilebilirlik (Y9) & 5,335 & 0,01 & 0,1 & 0,2 & 0,2 & 0,2 \\
\hline Teknolojik olgunluk (Y10) & 9,322 & 0,05 & 0,1 & 0,25 & 0,1 & 0,1 \\
\hline Hizmet ömrü (Y12) & 9,589 & 0,1 & 0,1 & 0,1 & 0,1 & 0,01 \\
\hline $\begin{array}{l}\text { Arıza / Kaza Riskinin } \\
\text { Düşüklüğü }(Y 8)\end{array}$ & 10,056 & 0,01 & 0,2 & 0,15 & 0,05 & 0,01 \\
\hline Arazi ihtiyacı (Y4) & 10,231 & 0,1 & 0,01 & 0,2 & 0,2 & 0,01 \\
\hline Teslim süresi (Y15) & 11,181 & 0,2 & 0,15 & 0,25 & 0,1 & 0,2 \\
\hline Güvenilirlik (Y6) & 11,202 & 0,5 & 0,2 & 0,1 & 0,15 & 0,05 \\
\hline $\begin{array}{l}\text { Kaynakların sürdürülebilirliği } \\
\text { ve öngörülebilirliği (Y17) }\end{array}$ & 11,952 & 0,4 & 0,05 & 0,2 & 0,05 & 0,25 \\
\hline $\begin{array}{l}\text { Üretim ve kurulumda } \\
\text { modülerlik }(Y 20)\end{array}$ & 12,037 & 0,2 & 0,1 & 0,25 & 0,1 & 0,01 \\
\hline Ekolojik etki (Y11) & 14,757 & 0,05 & 0,2 & 0,05 & 0,1 & 0,15 \\
\hline Su tüketimi (Y14) & 14,766 & 0,2 & 0,1 & 0,3 & 0,2 & 0,1 \\
\hline Gürültü (Y3) & 17,033 & 0,1 & 0,05 & 0,5 & 0,15 & 0,01 \\
\hline Sera emisyonları $(Y 7)$ & 17,096 & 0,1 & 0,15 & 0,05 & 0,15 & 0,05 \\
\hline $\begin{array}{l}\text { Diş çevre ile koordinasyon } \\
(Y 18)\end{array}$ & 17,681 & 0,25 & 0,01 & 0,3 & 0,2 & 0,01 \\
\hline Atık üretim miktarı (Y16) & 18,173 & 0,1 & 0,05 & 0,05 & 0,05 & 0,15 \\
\hline
\end{tabular}


Ortalama değerin karşılaştırmalı önemi tamamlandıktan sonra, Eş (1), Eş (2) ve Eş (3) dikkate alınarak gerekli çözümler yapılmış ve değerlendirme kriterlerinin göreceli ağırlıkları $\left(w_{j}\right)$ belirlenmiştir (Tablo 5).

Tablo 5

Kriterlerin karar vericiler tarafından belirlenen göreceli ağırlıkları

\begin{tabular}{|c|c|c|c|c|c|c|c|c|}
\hline Kriterler & $\begin{array}{l}\mathrm{KV} 1 \\
\left(w_{j}\right)\end{array}$ & $\begin{array}{l}\mathrm{KV} 2 \\
\left(w_{j}\right)\end{array}$ & $\begin{array}{l}\mathrm{KV} 3 \\
\left(w_{j}\right)\end{array}$ & $\begin{array}{l}\mathrm{KV} 4 \\
\left(w_{j}\right)\end{array}$ & $\begin{array}{l}\mathrm{KV} 5 \\
\left(w_{j}\right)\end{array}$ & $\begin{array}{l}\text { Ağırlıkların } \\
\text { Aritmetik } \\
\text { Ortalaması }\end{array}$ & $\begin{array}{c}\text { Aritmetik } \\
\text { Ortalama } \\
(\%)\end{array}$ & $\begin{array}{l}\text { Kümülatif } \\
\text { Toplam }\end{array}$ \\
\hline
\end{tabular}

\begin{tabular}{|c|c|c|c|c|c|c|c|c|}
\hline Maliyet (Y1) & 0,128 & 0,138 & 0,201 & 0,222 & 0,139 & 0,166 & 16,565 & 16,565 \\
\hline Verimlilik (Y13) & 0,107 & 0,131 & 0,161 & 0,148 & 0,116 & 0,133 & 13,258 & 29,822 \\
\hline İş imkânı (Y5) & 0,082 & 0,087 & 0,115 & 0,099 & 0,097 & 0,096 & 9,597 & 39,420 \\
\hline Elde edilebilirlik miktarı (Y2) & 0,078 & 0,080 & 0,088 & 0,082 & 0,092 & 0,084 & 8,410 & 47,829 \\
\hline Devlet teşvikleri (Y19) & 0,075 & 0,069 & 0,073 & 0,059 & 0,061 & 0,067 & 6,749 & 54,579 \\
\hline Sosyal kabul edilebilirlik (Y9) & 0,074 & 0,063 & 0,061 & 0,049 & 0,051 & 0,060 & 5,963 & 60,542 \\
\hline Teknolojik olgunluk (Y10) & 0,070 & 0,057 & 0,049 & 0,045 & 0,047 & 0,054 & 5,351 & 65,893 \\
\hline Hizmet ömrü (Y12) & 0,064 & 0,052 & 0,045 & 0,040 & 0,046 & 0,049 & 4,940 & 70,833 \\
\hline $\begin{array}{l}\text { Arıza / Kaza Riskinin Düşüklüğü } \\
\text { (Y8) }\end{array}$ & 0,063 & 0,043 & 0,039 & 0,039 & 0,046 & 0,046 & 4,590 & 75,424 \\
\hline Arazi ihtiyacı (Y4) & 0,058 & 0,043 & 0,032 & 0,032 & 0,045 & 0,042 & 4,200 & 79,624 \\
\hline Teslim süresi (Y15) & 0,048 & 0,037 & 0,026 & 0,029 & 0,038 & 0,036 & 3,558 & 83,182 \\
\hline Güvenilirlik (Y6) & 0,032 & 0,031 & 0,023 & 0,025 & 0,036 & 0,030 & 2,955 & 86,137 \\
\hline $\begin{array}{l}\text { Kaynakların sürdürülebilirliği ve } \\
\text { öngörülebilirliği (Y17) }\end{array}$ & 0,023 & 0,030 & 0,020 & 0,024 & 0,029 & 0,025 & 2,497 & 88,634 \\
\hline $\begin{array}{l}\text { Üretim ve kurulumda modülerlik } \\
(Y 20)\end{array}$ & 0,019 & 0,027 & 0,016 & 0,022 & 0,028 & 0,022 & 2,239 & 90,873 \\
\hline Ekolojik etki (Y11) & 0,018 & 0,022 & 0,015 & 0,020 & 0,025 & 0,020 & 2,002 & 92,876 \\
\hline Su tüketimi (Y14) & 0,015 & 0,020 & 0,011 & 0,017 & 0,022 & 0,017 & 1,721 & 94,597 \\
\hline Gürültü $(Y 3)$ & 0,014 & 0,019 & 0,008 & 0,014 & 0,022 & 0,015 & 1,550 & 96,146 \\
\hline Sera emisyonları (Y7) & 0,012 & 0,017 & 0,007 & 0,013 & 0,021 & 0,014 & 1,408 & 97,554 \\
\hline Dış çevre ile koordinasyon (Y18) & 0,010 & 0,017 & 0,006 & 0,010 & 0,021 & 0,013 & 1,275 & 98,829 \\
\hline Atık üretim miktarı (Y16) & 0,009 & 0,016 & 0,005 & 0,010 & 0,018 & 0,012 & 1,171 & 100,000 \\
\hline
\end{tabular}


Tablo 5'de yer alan nihai göreceli önem tablosu șu şekilde değerlendirilmiştir; başlangıçta yer alan 20 kriter azalan önem sırasına göre sıralanarak Pareto Analizine başvurulmuştur. $\mathrm{Bu}$ analiz yardımıyla iyileştirmelerin öncelikle hangi alanlara uygulanacağı belirlenir ve çalışma yürütülür (Özgüvenç, 2011). Literatürde "80-20 Kuralı" olarak da adlandırılan bu kalite aracına göre, "problemlerin \%80'lik kısmına \%20'lik aktivitenin neden olması ve bu önemli \%20'lik payın üzerinde yoğunlaşılması" sonucuna varılmaktadır. Bu sebeple, kümülatif toplamda yer alan değerler doğrultusunda 80-20 kuralına göre aşağıda yer alan kriterler, daha doğru sonuç vermesi adına TOPSIS yönteminde ağırlıklarıyla ile birlikte kullanılmasına karar verilmiştir;
1. Maliyet (Y1)
2. Verimlilik (Y13)
3. İşimkânı (Y5)

4. Elde edilebilirlik miktarı (Y2)

5. Devlet teşvikleri (Y19)

6. Sosyal kabul edilebilirlik (Y9)

7. Teknolojik olgunluk (Y10)

8. Hizmet ömrü (Y12)

9. Arıza / Kaza Riskinin Düşüklügü $(Y 8)$

10. Arazi ihtiyacı $(Y 4)$

\subsubsection{TOPSIS Uygulama Adımları}

Kurulacak olan tesisin hangi yenilenebilir enerji kaynağının seçilmesi gerektiğine dair TOPSIS uygulama adımları aşağıda gösterilmektedir.

Adım 1: Alternatifler ve değerlendirme kriterlerden oluşan başlangıç karar matrisi Çizelge 6'da verilmiştir.

Tablo 6

Alternatifler ve değerlendirme kriterlerinden oluşan karar matrisi

\begin{tabular}{|c|c|c|c|c|c|c|c|c|c|c|}
\hline \multirow{2}{*}{$\begin{array}{l}\text { Alternatifler } \\
\text { Yenilenebilir } \\
\text { Enerji } \\
\text { Kaynakları }\end{array}$} & \multicolumn{10}{|c|}{ Değerlendirme Kriterleri } \\
\hline & $\begin{array}{c}\mathrm{Y} 1 \\
(\$ / \mathrm{kW})\end{array}$ & $\begin{array}{c}\mathrm{Y} 19 \\
(\$ / \mathrm{kW})\end{array}$ & $\begin{array}{c}\text { Y2 } \\
(\%)\end{array}$ & $\begin{array}{l}\text { Y13 } \\
(\%)\end{array}$ & $\begin{array}{l}\text { Y5 (kişi } \\
\text { /MW) }\end{array}$ & Y9 & Y10 & $\begin{array}{l}\text { Y12 } \\
\text { (yil) }\end{array}$ & Y8 & $\begin{array}{c}\mathrm{Y} 4 \\
\left(\mathrm{~km}^{2} /\right. \\
\mathrm{MW})\end{array}$ \\
\hline $\mathrm{A} 1$ & 2213 & 11 & 0,2 & 26 & 0,40 & 0,1340 & 3 & 25 & 17 & 10 \\
\hline A2 & 3873 & 22,5 & 0,5 & 21 & 0,53 & 0,1137 & 2 & 25 & 16,6 & 11 \\
\hline A3 & 4114 & 18,9 & 0,8 & 40 & 1 & 0,1270 & 5 & 20 & 10 & 25 \\
\hline A4 & 5000 & 15 & 0,4 & 30 & 0,45 & 0,15 & 5 & 20 & 8 & 20 \\
\hline A5 & 2500 & 10 & 0,3 & 15 & 0,30 & 0,05 & 3 & 30 & 15 & 20 \\
\hline A6 & 2936 & 9,6 & 0,5 & 90 & 0,33 & 0,0479 & 5 & 30 & 11 & 10 \\
\hline A7 & 4362 & 13,2 & 0,3 & 16 & 2,13 & 0,1312 & 4 & 25 & 9 & 38 \\
\hline
\end{tabular}

Tablo 6'da Türkiye verileri üzerinden değerlendirilen rüzgâr enerjisi, güneş enerjisi, hidroelektrik enerji, jeotermal enerji ve biyokütle enerjilerinin değerlendirme kriterlerinden bir kısmı Özcan ve arkadaşlarının (2017) çalışmalarından alınmıştır. Hidrojen enerjisi, dalga enerjisi ve bazı değerlendirme kriterleri uzman görüşü alınarak karar matrisi oluşturulmuştur.

Adım 2: Başlangıç karar matrisini standartlaştırılması adımıdır. $\mathrm{Bu}$ adımda Eșitlik (5)'den yararlanılmaktadır. Tablo 7'de standartlaştırılmış karar matrisi görülmektedir. 
Tablo 7

Standartlaştırılmış karar matrisi

\begin{tabular}{|c|c|c|c|c|c|c|c|c|c|c|}
\hline \multirow{2}{*}{$\begin{array}{l}\text { Alternatifler } \\
\text { Yenilenebilir } \\
\text { Enerji } \\
\text { Kaynakları }\end{array}$} & \multicolumn{10}{|c|}{ Değerlendirme Kriterleri } \\
\hline & $\begin{array}{c}\mathrm{Y1} \\
(\$ / \mathrm{kW} \\
\text { ) }\end{array}$ & $\begin{array}{c}\mathrm{Y} 19 \\
(\$ / \mathrm{kW})\end{array}$ & Y2 (\%) & $\begin{array}{l}\text { Y13 } \\
(\%)\end{array}$ & $\begin{array}{c}\mathrm{Y} 5 \\
\text { (kişi } \\
\text { /MW) }\end{array}$ & Y9 & Y10 & $\begin{array}{l}\text { Y12 } \\
\text { (yll) }\end{array}$ & Y8 & $\begin{array}{c}\mathrm{Y} 4 \\
\left(\mathrm{~km}^{2} /\right. \\
\mathrm{MW})\end{array}$ \\
\hline $\mathrm{A} 1$ & 0,226 & 0,277 & 0,162 & 0,235 & 0,158 & 0,443 & 0,282 & 0,374 & 0,500 & 0,177 \\
\hline A2 & 0,396 & 0,567 & 0,406 & 0,190 & 0,210 & 0,376 & 0,188 & 0,374 & 0,488 & 0,195 \\
\hline A3 & 0,420 & 0,476 & 0,649 & 0,362 & 0,396 & 0,420 & 0,470 & 0,299 & 0,294 & 0,443 \\
\hline A4 & 0,511 & 0,378 & 0,324 & 0,272 & 0,178 & 0,496 & 0,470 & 0,299 & 0,235 & 0,354 \\
\hline A5 & 0,256 & 0,252 & 0,243 & 0,136 & 0,119 & 0,165 & 0,282 & 0,448 & 0,441 & 0,354 \\
\hline A6 & 0,300 & 0,242 & 0,406 & 0,815 & 0,131 & 0,158 & 0,470 & 0,448 & 0,324 & 0,177 \\
\hline A7 & 0,446 & 0,333 & 0,243 & 0,145 & 0,843 & 0,434 & 0,376 & 0,374 & 0,265 & 0,673 \\
\hline
\end{tabular}

Adım 3: $\mathrm{Bu}$ adımda değerlendirme kriterleri içinpuanlar SWARA metodundan elde edilmektedir. SWARA metodundan elde edilen ağırlıklar toplam 1 edecek şekilde güncellenmektedir. Belirlenen ağırlıklar Tablo 8'de gösterilmektedir.

Tablo 8

Değerlendirme kriterlerinin ağırlıkları

\begin{tabular}{lll}
\hline Kriterler & Ağırlıklar & $\begin{array}{l}\text { Güncellenen } \\
\left.\text { Ağırlıklar ( } \mathrm{w}_{\mathrm{j}}\right)\end{array}$ \\
\hline Maliyet (Y1) & 0,166 & 0,208281 \\
Verimlilik (Y13) & 0,133 & 0,166876 \\
İş imkânı (Y5) & 0,096 & 0,120452 \\
Elde edilebilirlik miktarı (Y2) & 0,084 & 0,105395 \\
Devlet teşvikleri (Y19) & 0,067 & 0,084065 \\
Sosyal kabul edilebilirlik (Y9) & 0,060 & 0,075282 \\
Teknolojik olgunluk (Y10) & 0,054 & 0,067754 \\
Hizmet ömrü (Y12) & 0,049 & 0,061481 \\
Arıza / Kaza Riskinin Düşüklüğü (Y8) & 0,046 & 0,057716 \\
Arazi ihtiyacı (Y4) & 0,042 & 0,052698 \\
\hline
\end{tabular}


Tablo 9'da belirlenen ağırlıklar ile standartlaștırılmış karar matrisi çarpılarak ağırlıklı standart karar matris elde edilmektedir.

Tablo 9

Ağırlıklı standart karar matrisi

\begin{tabular}{|c|c|c|c|c|c|c|c|c|c|c|}
\hline \multirow{2}{*}{$\begin{array}{l}\text { Alternatifler } \\
\text { Yenilenebilir } \\
\text { Enerji } \\
\text { Kaynakları }\end{array}$} & \multicolumn{10}{|c|}{ Değerlendirme Kriterleri } \\
\hline & $\begin{array}{c}\mathrm{Y} 1 \\
(\$ / \mathrm{kW})\end{array}$ & $\begin{array}{c}\mathrm{Y} 19 \\
(\$ / \mathrm{kW})\end{array}$ & Y2 (\%) & $\begin{array}{l}\text { Y13 } \\
(\%)\end{array}$ & $\begin{array}{l}\text { Y5 (kişi } \\
\text { /MW) }\end{array}$ & Y9 & Y10 & $\begin{array}{l}\text { Y12 } \\
\text { (yll) }\end{array}$ & Y8 & $\begin{array}{c}\mathrm{Y} 4 \\
\left(\mathrm{~km}^{2} / \mathrm{M}\right. \\
\mathrm{W})\end{array}$ \\
\hline $\mathrm{A} 1$ & 0,047 & 0,023 & 0,017 & 0,039 & 0,019 & 0,033 & 0,019 & 0,023 & 0,029 & 0,009 \\
\hline A2 & 0,082 & 0,048 & 0,043 & 0,032 & 0,025 & 0,028 & 0,013 & 0,023 & 0,028 & 0,010 \\
\hline A3 & 0,087 & 0,040 & 0,068 & 0,060 & 0,048 & 0,032 & 0,032 & 0,018 & 0,017 & 0,023 \\
\hline $\mathrm{A} 4$ & 0,106 & 0,032 & 0,034 & 0,045 & 0,021 & 0,037 & 0,032 & 0,018 & 0,014 & 0,019 \\
\hline A5 & 0,053 & 0,021 & 0,026 & 0,023 & 0,014 & 0,012 & 0,019 & 0,028 & 0,025 & 0,019 \\
\hline A6 & 0,062 & 0,020 & 0,043 & 0,136 & 0,016 & 0,012 & 0,032 & 0,028 & 0,019 & 0,009 \\
\hline A7 & 0,093 & 0,028 & 0,026 & 0,024 & 0,102 & 0,033 & 0,025 & 0,023 & 0,015 & 0,035 \\
\hline
\end{tabular}

Adım 4: Bu adımda eşitlik (6) ve (7) denklemleri yardımıyla pozitif ve negatif ideal çözüm kümeleri oluşturulmaktadır. Çözüm kümeleri, her sütun için en küçük değer (negatif ideal uzaklık) $A^{-}$ve her sütun için en büyük değer (pozitif ideal uzaklık) için $A^{+}$olarak oluşturulur.

$$
\begin{aligned}
& A^{-}=\left(\min _{\mathrm{i}} \mathrm{v}_{\mathrm{i} 1} ; \min _{\mathrm{i}} \mathrm{v}_{\mathrm{i} 2} ; \min _{\mathrm{i}} \mathrm{v}_{\mathrm{i} 3} ; \min _{\mathrm{i}} \mathrm{v}_{\mathrm{i} 4} ; \min _{\mathrm{i}} \mathrm{v}_{\mathrm{i} 5} ; \min _{\mathrm{i}} \mathrm{v}_{\mathrm{i} 6} ; \min _{\mathrm{i}} \mathrm{v}_{\mathrm{i} 7} ; \min _{\mathrm{i}} \mathrm{v}_{\mathrm{i} 8} ; \min _{\mathrm{i}} \mathrm{v}_{\mathrm{i} 9} ; \min _{\mathrm{i}} \mathrm{v}_{\mathrm{i} 10}\right) \\
& \mathrm{A}^{-}=(0,047 ; 0,020 ; 0,017 ; 0,023 ; 0,014 ; 0,012 ; 0,013 ; 0,018 ; 0,014 ; 0,009) \\
& \mathrm{A}^{+}=\left(\max _{\mathrm{i}} \mathrm{v}_{\mathrm{i} 1} ; \max _{\mathrm{i}} \mathrm{v}_{\mathrm{i} 2} ; \max _{\mathrm{i}} \mathrm{v}_{\mathrm{i} 3} ; \max _{\mathrm{i}} \mathrm{v}_{\mathrm{i} 4} ; \max _{\mathrm{i}} \mathrm{v}_{\mathrm{i} 5} ; \max _{\mathrm{i}} \mathrm{v}_{\mathrm{i} 6} ; \max _{\mathrm{i}} \mathrm{v}_{\mathrm{i} 7} ; \max _{\mathrm{i}} \mathrm{v}_{\mathrm{i} 8} ; \max _{\mathrm{i}} \mathrm{v}_{\mathrm{i} 9} ; \max _{\mathrm{i}} \mathrm{v}_{\mathrm{i} 10}\right) \\
& \mathrm{A}^{+}=(0,106 ; 0,048 ; 0,068 ; 0,136 ; 0,102 ; 0,037 ; 0,032 ; 0,028 ; 0,029 ; 0,035)
\end{aligned}
$$


Adım 5: Elde edilen alternatiflerin incelenen kriterler için sapma değerleri Pozitif İdeal Uzaklık $\left(S_{i}^{+}\right)$ve Negatif İdeal Uzaklık $\left(S_{i}^{-}\right)$ölçüsü olarak adlandırılmaktadır. Pozitif ideal çözüm kümesinden sapma değerleri hesaplanırken eşitlik (8) numaralı formül, negatif ideal çözüm kümesinden sapma değerleri hesaplanırken eşitlik (9) numaralı formülden yararlanılır (Ertuğrul ve Özçil, 2014). Tablo 10 'da pozitif ve negatif ideal uzaklıkları gösterilmektedir.

Tablo 10

Pozitif ideal uzaklıkları ve toplamları

\begin{tabular}{ccc}
\hline Yenilenebilir Enerji Kaynakları & $\mathrm{S}_{\mathrm{i}}^{+}$ & $\mathrm{S}_{\mathrm{i}}^{-}$ \\
\hline $\mathrm{A} 1$ & 0,155 & 0,032 \\
$\mathrm{~A} 2$ & 0,138 & 0,058 \\
$\mathrm{~A} 3$ & 0,098 & 0,090 \\
$\mathrm{~A} 4$ & 0,130 & 0,074 \\
A5 & 0,164 & 0,022 \\
A6 & 0,110 & 0,119 \\
A7 & 0,123 & 0,106 \\
\hline
\end{tabular}

Adım 6: Bu adımda ideal çözüme göreli yakınlık $\left(C_{i}^{*}\right)$ hesaplama işlemi yapılmaktadır. İdeal noktaya göre yakınlık değerleri hesaplanırken pozitif ideal $\left(S_{i}^{+}\right)$ve negatif ideal $\left(S_{i}^{-}\right)$uzaklığa göreli yakınlık değerleri kullanılmaktadır. Çizelge $11^{\prime}$ de, Çizelge $10^{\prime} \mathrm{da}$ bulunan pozitif ideal uzaklık $\left(S_{i}^{+}\right)$ve negatif ideal uzaklık $\left(S_{i}^{-}\right)$değerleri ve eşitlik (10)'da yer alan denklemdeki eşitlik kullanılarak $\left(C_{i}^{*}\right)$ değeri bulunmaktadır.

Tablo 11

İdeal çözüme göreli yakınlığın hesaplanması

\begin{tabular}{ccc}
\hline Yenilenebilir Enerji Kaynakları & $\mathrm{C}_{\mathrm{i}}^{*}$ & Siralama \\
\hline A1 & 0,171 & 6 \\
A2 & 0,296 & 5 \\
A3 & 0,479 & 2 \\
A4 & 0,363 & 4 \\
A5 & 0,118 & 7 \\
A6 & 0,520 & 1 \\
A7 & 0,463 & 3 \\
\hline
\end{tabular}

Tablo 11'de de görüldüğü gibi $\left(C_{i}^{*}\right)$ değerleri yenilenebilir enerji kaynaklarının sıralaması olarak ortaya çıkmaktadır. Bölgede hidroelektrik enerji santralinin kurulması alternatifi değerlendirilmesi gereken ilk alternatif olarak görülmektedir. Bu enerji kaynağını sırasıyla biyokütle enerjisi, jeotermal enerji, hidrojen enerjisi, güneş enerjisi, rüzgâr enerjisi ve dalga enerjisi takip etmektedir.

\section{AHP Yöntemi ile Karşılaştırmalı Analiz}

SWARA yöntemi kullanılarak belirlenen her bir kritere yönelik önem dereceleri (ağırlıkları) bu başlık altında tekrar aynı karar vericilerden alınan görüşler Analitik Hiyerarşi Prosesi (AHP) yöntemi ile değerlendirilmiş ve TOPSIS ile sıralama yeniden yapılarak çıkan sonuçlar karşılaştırılmıștır.

AHP' de ölçme yapabilmek ve ikili karşılaştırma matrislerini oluşturulabilmek için, Saaty tarafından geliştirilen göreli önem ölçeği kullanılmaktadır (Saaty, 1994). Karşılaştırma ölçeğinde alt sınır 1, üst sınır 9 ile sınırlandırılmıştır. 2, 4, 6, 8 ara değerlerdir. 
İkili karşılaștırmalar, AHP'nin en önemli aşamasıdır. İkili karşılaștırmaları elde etmek için göreceli ölçüm değerleri kullanılır. Bunlardan elde edilen bilgilere göre AHP'de yargilar bir matrise dönüştürülür.

Kriterler arası karşılaştırma matrisi, 10x10 boyutlu bir kare matristir ve bu matrisin köșegeni üzerindeki matris bileşenleri 1 değerini alır. Çünkü burada söz konusu boyut kendisi ile karşılaştırılmaktadır. Boyutların karşılaştırılması, birbirlerine göre sahip oldukları önem değerlerine göre birebir ve karşılıklı yapılır. Bu karşılaştırma ve değer atama işlemlerinde SWARA yöntemi için de danışılan 5 karar vericiden görüş alınmıştır. 5 farklı kişiden gelen sonuçların her bir karşılaştırma matrisi değerinin geometrik ortalaması alınarak, nihai karşılaştırma matrisi oluşturulmuştur (Tablo 12).

İkili karşılaştırma matrislerinin oluşturulmasından sonra her boyutun önem derecelerinin hesaplanmasına geçilmektedir. Sentez aşaması olarak bilinen bu aşama, en büyük öz değer ve bu öz değere karşılık gelen öz vektörün hesaplanmasını ve normalize edilmesini kapsamaktadır (Kuruüzüm ve Atsan, 2001). Hesaplanan özvektör değerleri her bir boyutun önem derecesini yani ağırlıklarını belirtmektedir. AHP yönteminin önem derecesi belirleme matrisinden faydalanılarak ağırlıklar hesaplanmıştır (Tablo 13).

AHP yönteminde diğer bir önemli konu karar vericilerin yargılarındaki tutarlılıktır. Karar vericinin kriterler arasında kıyaslama yaparken tutarlı davranıp davranmadığını ölçmek için CR şeklinde kısaltılan Tutarlılık Oranından yararlanılmaktadır. Tutarlılık Oranı (CR) ile bulunan öncelik vektörünün ve dolayısıyla faktörler arasında yapılan birebir karşılaștırmaların tutarlılığın test edilebilmesi imkânını sağlamaktadır. Bu analiz sonucunda Tutarlılık Oranı 0,09 olarak hesaplanmıştır. Hesaplanan CR değerinin 0,10'dan küçük olması karar vericilerin yaptığı karşılaştırmaların tutarlı olduğunu göstermektedir.

Tablo 12

Uzman kişiler tarafından oluşturulan karşılaştırma matrisi

\begin{tabular}{ccccccccccc}
\hline & $(\mathrm{Y} 1)$ & $(\mathrm{Y} 13)$ & $(\mathrm{Y} 5)$ & $(\mathrm{Y} 2)$ & $(\mathrm{Y} 19)$ & $(\mathrm{Y} 9)$ & $(\mathrm{Y} 10)$ & $(\mathrm{Y} 12)$ & $(\mathrm{Y} 8)$ & $(\mathrm{Y} 4)$ \\
\hline$(\mathrm{Y} 1)$ & 1,00 & 2,19 & 2,56 & 2,64 & 2,94 & 3,36 & 2,25 & 3,02 & 3,76 & 3,26 \\
$(\mathrm{Y} 13)$ & 0,46 & 1,00 & 3,47 & 1,35 & 2,15 & 3,13 & 2,83 & 3,99 & 4,34 & 1,99 \\
$(\mathrm{Y} 5)$ & 0,39 & 0,29 & 1,00 & 1,06 & 2,99 & 3,01 & 1,40 & 2,07 & 3,25 & 1,30 \\
$(\mathrm{Y} 2)$ & 0,38 & 0,74 & 0,94 & 1,00 & 2,13 & 3,32 & 3,63 & 1,28 & 1,90 & 0,89 \\
$(\mathrm{Y} 19)$ & 0,34 & 0,47 & 0,33 & 0,47 & 1,00 & 1,49 & 2,93 & 1,48 & 1,40 & 1,38 \\
$(\mathrm{Y} 9)$ & 0,30 & 0,32 & 0,33 & 0,30 & 0,67 & 1,00 & 0,65 & 1,43 & 1,25 & 2,37 \\
$(\mathrm{Y} 10)$ & 0,44 & 0,35 & 0,71 & 0,28 & 0,34 & 1,53 & 1,00 & 2,78 & 0,88 & 1,24 \\
$(\mathrm{Y} 12)$ & 0,33 & 0,25 & 0,48 & 0,78 & 0,67 & 0,70 & 0,36 & 1,00 & 0,41 & 2,38 \\
$(\mathrm{Y} 8)$ & 0,27 & 0,23 & 0,31 & 0,53 & 0,71 & 0,80 & 1,14 & 2,45 & 1,00 & 1,74 \\
$(\mathrm{Y} 4)$ & 0,31 & 0,50 & 0,77 & 1,12 & 0,72 & 0,42 & 0,81 & 0,42 & 0,57 & 1,00 \\
\hline
\end{tabular}


Tablo 13

Kriterlerin özvektörleri (önem dereceleri)

\begin{tabular}{lc}
\hline KRITERLER & ÖZVEKTÖR \\
\hline Maliyet (Y1) & 0,21 \\
Verimlilik (Y13) & 0,18 \\
Elde edilebilirlik miktarı (Y2) & 0,12 \\
İșimkânı (Y5) & \\
Devlet teşvikleri (Y19) & 0,11 \\
Teknolojik olgunluk (Y10) & 0,08 \\
Sosyal kabul edilebilirlik (Y9) & 0,07 \\
Hizmet ömrü (Y12) & 0,06 \\
Arıza / Kaza Riskinin Düşüklüğü (Y8) & 0,06 \\
Arazi ihtiyacı (Y4) & 0,06 \\
\hline
\end{tabular}

Ağırlıkların AHP yöntemi ile belirlenmesinin ardından Tablo 8'de yer alan ağırlıklar güncellenerek yeni ağırlıklar Tablo 13'te yer alan şekli ile yeniden TOPSIS yönteminde çözüme girerek ve çıkan sıralama karşılaştırılmaktadır. Tablo 14'te SWARA

tabanlı TOPSIS yöntemiyle AHP tabanlı TOPSIS yöntemi kıyaslanmaktadır. Sıralama değişmemekle birlikte oransal olarak bazı değișiklikler gerçekleşmektedir. $\mathrm{Bu}$ değişim Şekil 1'de gösterilmektedir.

Tablo 14

İdeal çözüme göreli yakınlığın hesaplanması sonuçları ve karşılaştırılması

\begin{tabular}{ccccc}
\hline $\begin{array}{c}\text { Yenilenebilir Enerji } \\
\text { Kaynakları }\end{array}$ & $\begin{array}{c}\text { SWARA Tabanl } \\
\text { TOPSISC }\end{array}$ & Siralama & $\begin{array}{c}\text { AHP Tabanl } \\
\text { TOPSISC }_{i}^{*}\end{array}$ & Siralama \\
\hline A1 & 0,171 & 6 & 0,163 & 6 \\
A2 & 0,296 & 5 & 0,291 & 5 \\
A3 & 0,479 & 2 & 0,486 & 2 \\
A4 & 0,363 & 4 & 0,362 & 7 \\
A5 & 0,118 & 7 & 0,119 & 1 \\
A6 & 0,520 & 1 & 0,550 & 3 \\
A7 & 0,463 & 3 & 0,428 & \\
\hline
\end{tabular}

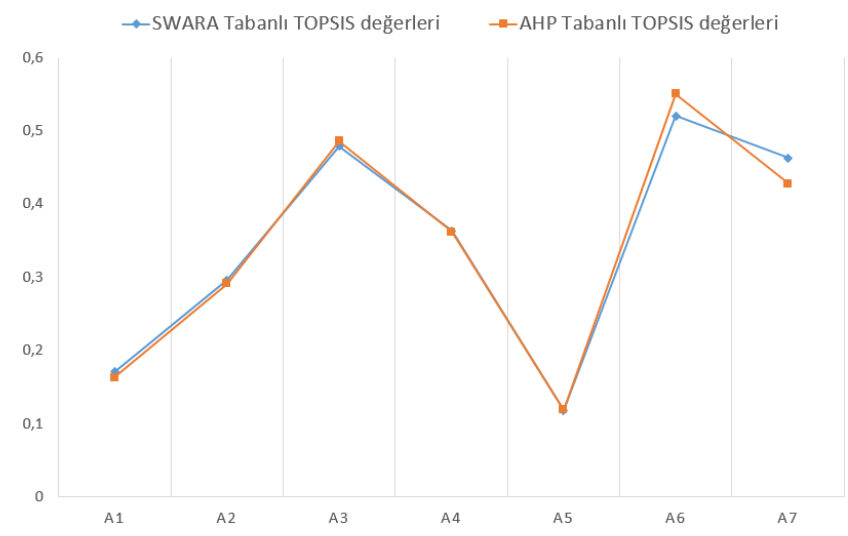

Şekil 1 SWARA tabanlı TOPSIS ile AHP tabanlı TOPSIS alternatiflerinin kıyaslanması 


\section{Sonuç ve Tartışmalar}

Günümüzde nüfusun artması ve teknolojinin gelişmesiyle birlikte enerji kaynaklarının kullanımı giderek artmaktadır. Enerji kaynaklarının kullanımının artması ile kaynaklar giderek azalmakta ve yeni enerji kaynaklarına olan ihtiyaç ve arayış artmaktadır. Bu ihtiyaçlar ve arayışlar sonucunda yenilenebilir enerji kaynaklarının kullanım alanı her geçen gün artmaktadır. $\mathrm{Bu}$ çalışmada Türkiye'de genel olarak hangi yenilenebilir enerji kaynağının işlenmesi gerektiği problemi çok boyutlu şekilde incelenmiştir. Yenilenebilir enerji kaynakları olarak; rüzgâr enerjisi, biyokütle enerjisi, güneş enerjisi, hidrojen enerjisi, dalga enerjisi, hidroelektrik enerji ve jeotermal enerji dikkate alınmaktadır. Çalışmada Çok Kriterli Karar Verme yöntemlerinden SWARA ve TOPSIS yöntemi bütünleşik olarak uygulanmıștır. SWARA ile entegre TOPSIS yönteminin kullanım nedenlerinin başında karar vericilere kriter öncelikleri belirleme konusunda daha fazla firsat vermesi gelmektedir. İki farklı yöntem ile ağırlıklandırmaların uygun bir şekilde yapılması ve sıralamanın uygun şekilde elde edilmesi amaçlanmaktadır. Ele alınan kaynakların karşılaştırılması için literatürden birçok farklı değerlendirme kriteri derlenerek uzman görüşleri alınmış ve SWARA metoduyla en önemli kriterler elde edilmiștir. Bu değerlendirme kriterleri; maliyet, verimlilik, iş imkânı, elde edilebilirlik miktarı, devlet teşvikleri, sosyal kabul edilebilirlik, teknolojik olgunluk, hizmet ömrü, arıza/kaza riskinin düşüklüğü ve arazi ihtiyacl olarak belirlenmiștir. Yenilenebilir enerji kaynaklarının seçimi için önemli olan kriterler, yenilenebilir enerji kaynakları alternatifleri (rüzgâr enerjisi, biyokütle enerjisi, güneş enerjisi, hidrojen enerjisi, dalga enerjisi, hidroelektrik enerji ve jeotermal enerji) için TOPSIS metoduyla değerlendirilmiştir. Geliştirilen bütünleşik metodun sonuçlarında, Türkiye'de hidroelektrik enerji santralinin kurulması gerektiği ilk sırada görülmektedir. $\mathrm{Bu}$ enerji kaynağını sırasıyla biyokütle enerjisi, jeotermal enerji, hidrojen enerjisi, güneş enerjisi, rüzgâr enerjisi ve dalga enerjisi takip etmektedir. Çalışmanın sonucunda çıkan hidroelektrik enerji santrali Türkiye için uygun bir santral olacağı ortaya çımmaktadır. Gerçekleștirilen karşılaştırmalı analiz ile SWARA tabanlı TOPSIS yöntemi ile AHP tabanlı TOPSIS yöntemi kıyaslanarak sonuçlar karşılaştırılmaktadır ve elde edilen sonuçların tutarlı olduğu görülmektedir. Literatürde Alkan ve Albayrak,
(2020) yapmış olduğu çalışmada da aynı enerji santrali farklı yöntemler ve kriterler kullanılarak desteklenmektedir. Fuzzy COPRAS ve Fuzzy MULTIMOORA yöntemleri ile bölgeler için yenilenebilir enerji kaynakları alternatif sıralamaları elde edilmiş, Fuzzy COPRAS sonuçlarına göre, hidroelektrik enerji kaynağı on yedi bölge için uygun yenilenebilir enerji kaynağı alternatifi olarak tanımlanmıştır. Fuzzy MULTIMOORA sonuçlarına göre hidroelektrik enerji kaynağı on sekiz bölge için birinci sırada uygun yenilenebilir enerji kaynağ alternatifi olarak belirlenmiştir. Ülkemiz, coğrafi konumu nedeniyle birçok yenilenebilir enerji için yatırım yapılabilecek imkânlara sahip olduğu bir gerçektir. Enerji Bakanlığı'nın verilerine göre ülkemiz 36.000 MW hidroelektrik potansiyeli dünya teorik potansiyelinin $\% 1$ ' $\mathrm{i}$, ekonomik potansiyeli ise Avrupa ekonomik potansiyelinin \%16'sı olarak da alt yapısının ne kadar önemli olduğu anlaşılmaktadır. Enerji ve Tabii Kaynaklar Bakanlığı (2019-2023) Stratejik Planına göre de, 2023 hedefleri kapsamında ülkenin hidroelektrik potansiyelinin tümünün (36 GW civarı) elektrik üretimi için devreye sokulması amaçlanmıştır. Bu çalışmada, Türkiye'de potansiyeli olan yenilenebilir enerji kaynaklarının geniş çaplı bir değerlendirmesi yapılmaktadır. Literatürde yenilenebilir enerji kaynakları alternatiflerinin son yıllarda popüler bir çalışma olması literatüre kazanım sağlamıștır. Ayrıca, çalışmada yenilenebilir enerji kaynaklarının değerlendirilmesi için literatürdeki kriterlerin derlenmesi ve alanında uzman kişilerin görüşlerinin sağlanması nedeniyle literatüre katkı sağlayacağı düşünülmektedir. Gelecek çalışmalarda daha farklı yöntemler kullanılarak kaynakların değerlendirilmesi ve kıyaslanması tekrardan gerçekleştirilebilir.

\section{Araştırmacıların Katkısı}

$\mathrm{Bu}$ araştırmada Onur DERSE ve Emel YONTAR makale fikrinin hazırlanması, gözden geçirilmesi ve analiz sonuçlarının hazırlanması konularında, Onur DERSE TOPSIS yöntemi, Emel YONTAR SWARA yöntemi ile çözümlemeyi çalışarak katkı sağlamışlardır. 


\section{Çıkar Çatışması}

Yazarlar tarafından herhangi bir çıkar çatışması beyan edilmemiştir.

\section{Kaynaklar}

Aghdaie, M.H., Hashemkhani Zolfani, S., Zavadskas, E.K., 2013. Decision making in machine tool selection: an integrated approach with SWARA and COPRAS-G methods. Eng. Econ. 24, 5-17. doi: https://doi.org/10.5755/j01.ee.24.1.2822

Akyüz, Y., Soba, M. (2013). ELECTRE Yöntemiyle Tekstil Sektöründe Optimal Kuruluş Yeri Seçimi: Uşak İli Örneği. Uluslararası Yönetim İktisat ve Ișletme Dergisi, 9(19), 185-198. doi: https://doi.org/10.11122/ijmeb.2013.9.19.452

Alimardani, M., Hashemkhani Zolfani, S., Aghdaie, M. H., \& Tamošaitienè, J. (2013). A novel hybrid SWARA and VIKOR methodology for supplier selection in an agile environment. Technological And Economic Development Of Economy, 19(3), 533-548. doi: https://doi.org/10.3846/ $\underline{20294913.2013 .814606}$

Alizadeh, R., Soltanisehat, L., Lund, P. D., \& Zamanisabzi, H. (2020). Improving renewable energy policy planning and decision-making through a hybrid MCDM method. Energy Policy, 137, 111174. doi: https://doi.org/10.1016/ j.enpol.2019.111174

Alkan, Ö., \& Albayrak, Ö. K. (2020). Ranking of renewable energy sources for regions in Turkey by fuzzy entropy based fuzzy COPRAS and fuzzy MULTIMOORA. Renewable Energy, 162, 712-726. Doi: https://doi.org/10.1016/ j.renene.2020.08.062

Amer, M., \& Daim, T. U. (2011). Selection of renewable energy technologies for a developing county: a case of Pakistan. Energy For Sustainable Development, 15(4), 420-435. Doi: https://doi.org/10.1016/i.esd.2011.09.001

Aryanpur, V., Atabaki, M. S., Marzband, M., Siano, P., Ghayoumi, K. (2019). An overview of energy planning in Iran and transition pathways towards sustainable electricity supply sector. Renewable and Sustainable Energy Reviews, 112, 58-74. Doi: https://doi.org/10.1016/i.rser.2019.05.047

Aslan, H. M., Yıldız, M. S., Uysal, H. T. (2015). Afet İstasyonlarının Kuruluş Yeri Seçiminde Bulanık
TOPSIS Yönteminin Uygulanması: Düzce'de Bir Lokasyon Analizi. Siyaset, Ekonomi ve Yönetim Araştırmaları Dergisi, 3(2).

Beccali, M., Cellura, M., \& Mistretta, M. (2003). Decision-making in energy planning. Application of the Electre method at regional level for the diffusion of renewable energy technology. Renewable Energy, 28(13), 2063-2087. Doi: https://doi.org/10.1016/S0960-1481(03)00102-2

Benitez, J.M., Martin, J.C., Roman, C. (2007). Using Fuzzy Number for Measuring Quality of Service in The Hotel Industry, Tourism Management, 28(2), 544-555. Doi: https://doi.org/10.1016/ j.tourman.2006.04.018

Bianchini, A. (2018). 3PL Provider Selection by AHP and TOPSIS Methodology. Benchmarking: An International Journal, 25(1), 235-252 doi: https://doi.org/10.1108/BII-08-2016-0125

Bottani, E., Rizzi, A. (2006), A fuzzy TOPSIS Methodology to Support Outsourcing of Logistics Services, Supply Chain Management: $A n$ International Journal, 11(4), 294-308. Doi: https://doi.org/10.1108/13598540610671743

Bülbül, S., Köse A. (2011). Türk Gıda Şirketlerinin Finansal Performansının Çok Amaçlı Karar Verme Yöntemleriyle Değerlendirilmesi. Atatürk Üniversitesi Iktisadi ve İdari Bilimler Dergisi, 25. Doi: https://doi.org/10.16951/IIBD.54042

Dehnavi, A., Aghdam, I. N., Pradhan, B., \& Varzandeh, M. H. M. (2015). A new hybrid model using stepwise weight assessment ratio analysis (SWARA) technique and adaptive neuro-fuzzy inference system (ANFIS) for regional landslide hazard assessment in Iran. Catena, 135, 122-148 https://doi.org/10.1016/i.catena.2015.07.020

Demireli, E. (2010). TOPSIS Çok Kriterli Karar Verme Sistemi: Türkiye'deki Kamu Bankaları Üzerine Bir Uygulama. Girişimcilik ve Kalkınma Dergisi, 5(1), 102-112.

Demirtas, O. (2013). Evaluating the best renewable energy technology for sustainable energy planning. International Journal of Energy Economics and Policy, 3, 23.

Eleren, A., Karagül, M. (2008). 1986-2006 Türkiye Ekonomisinin Performans Değerlendirmesi, Celal Bayar Üniversitesi İ̈BF Yönetim ve Ekonomi Dergisi, 15(1), 1-14. 
Enerji ve Tabii Kaynaklar Bakanlığı 2019-2023 Stratejik Planı, Erișim adresi : https://sp.enerji.gov.tr/ETKB 2019_2023 Strate jik Plani.pdf.

Ertuğrul, İ., Özçil, A. (2014). Çok Kriterli Karar Vermede TOPSIS ve VIKOR Yöntemleriyle Klima Seçimi. Cankırı Karatekin Üniversitesi Íktisadi ve Ídari Bilimler Fakültesi Dergisi, 4(1), 267- 282.

Feng, C.M., Wang, R.T. (2001). Considering The Financial Ratios on The Performance Evaluation of Highway Bus İndustry, Transport Reviews, 21(4), 449-467. Doi: https://doi.org/10.1080/ $\underline{01441640010020304}$

Geyik, O., Tosun, M., Ünlüsoy, S., Hamurcu, M., Eren, T. (2016). Kitap Basımevi Seçiminde AHP ve TOPSIS Yöntemlerinin Kullanımı. Uluslararası Sosyal ve Eğitim Bilimleri Dergisi, 3(6), 106-126.

Ghenai, C., Albawab, M., \& Bettayeb, M. (2020). Sustainability indicators for renewable energy systems using multi-criteria decision-making model and extended SWARA/ARAS hybrid method. Renewable Energy, 146, 580-597. Doi: https://doi.org/10.1016/j.renene.2019.06.157

Gong, Z. T., Shi, Z. H. (2008). The TOPSIS Method Based on Covering Rough Sets. In Machine Learning and Cybernetics, 2008 International Conference on 4, 2430-2433. Doi: https://doi.org/10.1109/ICMLC.2008.4620814

Hashemkhani Zolfani, S., Aghdaie,M.H., Derakhti, A., Zavadskas, E.K.,Morshed Varzandeh, M.H., 2013a. Decisionmaking on business issues with foresight perspective; an application of new hybrid MCDM model in shopping mall locating. Expert Syst. Appl. 40, 7111-7121. Doi: https://doi.org/10.1016/i.eswa.2013.06.040

Hepbaşl, A., Özgener, O. (2004). A review on The Development of Wind Energy in Turkey, Renewable and Sustainable Energy Reviews, 8, 257-276.

Hsu T.K., Tsai, Y.F., and Wu, H.H. (2009), The Preference Analysis for Tourist Choice of Destination, A case study of Taiwan, Tourism Management, 30(2), 288-297. Doi: https://doi.org/10.1016/j.tourman.2008.07.011

Huang, W., Huang, Y.Y. (2012), Research on The Performance Evaluation Chonqing Electric Power Supply Bureaus Based on TOPSIS, Energy Procedia, 14, 899-905.
Hwang, C. L., Yoon, P., (1981), Multiple Attribute Decision Making In: Lecture Notes in Economics and Mathematical Systems, Springer-VerlagBerlin.

İlkiliç, C. (2012). Wind Energy and Assessment of Wind Energy Potential in Turkey, Renewable and Sustainable Energy Reviews, 16, 1165- 1173.

Kabak, M., \& Dağdeviren, M. (2014). Prioritization of renewable energy sources for Turkey by using a hybrid MCDM methodology. Energy Conversion and Management, 79, 25-33. Doi: https://doi.org/10.1016/j.enconman.2013.11.036

Kahraman, C., Kaya, İ., \& Cebi, S. (2009). A comparative analysis for multiattribute selection among renewable energy alternatives using fuzzy axiomatic design and fuzzy analytic hierarchy process. Energy, 34(10), 1603-1616.

Karabašević, D., Stanujkić, D., \& Urošević, S. (2015). The MCDM Model for Personnel Selection Based on SWARA and ARAS Methods. Management (1820-0222), 20(77). Doi: https://doi.org/10.7595/management.fon.2015. $\underline{0029}$

Karabasevic, D., Zavadskas, E. K., Turskis, Z., \& Stanujkic, D. (2016). The framework for the selection of personnel based on the SWARA and ARAS methods under uncertainties. Informatica, 27(1), 49-65.

Kaya, T., \& Kahraman, C. (2010). Multicriteria renewable energy planning using an integrated fuzzy VIKOR \& AHP methodology: The case of Istanbul. Energy, 35(6), 2517-2527.

Keršuliene, V., Zavadskas, E. K., \& Turskis, Z. (2010). Selection of rational dispute resolution method by applying new step-wise weight assessment ratio analysis (SWARA). Journal of Business Economics And Management, 11(2), 243-258. Doi: https://doi.org/10.3846/ibem.2010.12

Kuruüzüm, A., Atsan N., Analitik Hiyerarşi Yöntemi ve İşletmecilik Alanındaki Uygulamaları, Akdeniz Íktisadi İdari Bilimler Fakültesi Dergisi, 1, 2001.

Łaska, G. (2017). Wind Energy and multi-criteria analysis in making decisions on the location of wind farms. Procedia Engineering, 182, 418-424. Doi: https://doi.org/10.1016/j.proeng.2017.03.126

Lee, H. C., \& Chang, C. T. (2018). Comparative analysis of MCDM methods for ranking renewable energy sources in Taiwan. Renewable and Sustainable 
Energy Reviews, 92, 883-896. Doi: https://doi.org/10.1016/j.rser.2018.05.007

Ligus, M., \& Peternek, P. (2018). Determination of most suitable low-emission energy technologies development in Poland using integrated fuzzy AHP-TOPSIS method. Energy Procedia, 153, 101106. Doi: https://doi.org/10.1016/ j.egypro.2018.10.046

Madlener, R., Antunes, C. H., Dias, L. C. (2009). Assessing the performance of biogas plants with multi-criteria and data envelopment analysis. European Journal of Operational Research, 197(3), 1084-1094. Doi: https://doi.org/ 10.1016/j.ejor.2007.12.051

Martinez, A., Mustapha, Z. B., Campbell, R., and Bouragba, T. (2016, December). A multi-criteria methodology to select the best wave energy sites. In 2016 World Congress on Sustainable Technologies (WCST) (pp. 115-116). IEEE.

Mavi, R. K., Goh, M., \& Zarbakhshnia, N. (2017). Sustainable third-party reverse logistic provider selection with fuzzy SWARA and fuzzy MOORA in plastic industry. The International Journal of Advanced Manufacturing Technology, 91(5-8), 2401-2418. Doi: https://doi.org/10.1007/ s00170-016-9880-X

Mukherjee, A., Nath, P. (2005), An Empirical Assessment of Comparative Approaches to Service Quality Measurement, Journal of Services Marketing, 19(3), 174-184.

Nigim, K., Munier, N., \& Green, J. (2004). Prefeasibility MCDM tools to aid communities in prioritizing local viable renewable energy sources. Renewable energy, 29(11), 1775-1791.

Ömürbek, N., Üstündag, S., Helvacioglu, Ö. C. (2013). Kuruluș Yeri Seçiminde Analitik Hiyerarşi Süreci (AHP) Kullanımı: Isparta Bölgesi'nde Bir Uygulama. Çanakkale Onsekiz Mart Üniversitesi Yönetim Bilimleri Dergisi, 11(21), 101.

Özcan, E. C., Ünlüsoy, S., Tamer, E. (2017). ANP ve TOPSIS Yöntemleriyle Türkiye'de Yenilenebilir Enerji Yatırım Alternatiflerinin Değerlendirilmesi. Selçuk Üniversitesi Mühendislik, Bilim ve Teknoloji Dergisi, 5(2), 204219.

Özdemir, A. İ., Seçme, N. Y. (2009). İki Aşamalı Stratejik Tedarikçi Seçiminin Bulanık TOPSIS
Yöntemi ile Analizi, Afyon Kocatepe Üniversitesi I.I.B.F. Dergisi, 11(2), 79-112.

Özgüvenç $\quad$ D., Kalite $\quad$ Problemlerinin Sınıflandırılmasında Çok Kriterli Pareto Analizi, İstanbul Teknik Üniversitesi, Fen Bilimleri Enstitüsü, İşletme Mühendisliği, 2011.

Özkale, C., Celik, C., Turkmen, A. C., \& Cakmaz, E. S. (2017). Decision analysis application intended for selection of a power plant running on renewable energy sources. Renewable And Sustainable Energy Reviews, 70, 1011-1021.

Pal, M.N., Choudhury, K. (2009). Exploring the Dimensionality of Service Quality: An Application of TOPSIS in The Indian Banking İndustry, AsiaPacific Journal of Operational Research, 26(1), 115-133.

Rani, P., Mishra, A. R., Pardasani, K. R., Mardani, A., Liao, H., \& Streimikiene, D. (2019). A novel VIKOR approach based on entropy and divergence measures of Pythagorean fuzzy sets to evaluate renewable energy technologies in India. Journal of Cleaner Production, 238, 117936.

Raza, S. S., Janajreh, I., \& Ghenai, C. (2014). Sustainability index approach as a selection criteria for energy storage system of an intermittent renewable energy source. Applied Energy, 136, 909-920.

Ren, J., \& Sovacool, B. K. (2015). Prioritizing lowcarbon energy sources to enhance China's energy security. Energy Conversion And Management, 92, 129-136.

Rupf, G. V., Bahri, P. A., De Boer, K., McHenry, M. P. (2016). Development of a model for identifying the optimal biogas system design in Sub-Saharan Africa. In Computer Aided Chemical Engineering (Vol. 38, pp. 1533-1538).

Ruzgys, A., Volvačiovas, R., Ignatavičius, Č., \& Turskis, Z. (2014). Integrated evaluation of external wall insulation in residential buildings using SWARATODIM MCDM method. Journal of Civil Engineering and Management, 20(1), 103-110.

Saaty, T. L., Fundamentels of Decision Making And Priority Theory With Analytic Hierarchy Process, RWS publications, Pittsburg, 1994.

Shao, M., Han, Z., Sun, J., Xiao, C., Zhang, S., \& Zhao, Y. (2020). A review of multi-criteria decision making applications for renewable energy site 
selection. Renewable Energy. 157, 377-403. Doi: https://doi.org/10.1016/j.renene.2020.04.137

Shukla, A., Agarwal, P., Rana, R. S., Purohit, R. (2017). Applications of TOPSIS Algorithm on Various Manufacturing Processes: A Review. Materials Today: Proceedings, 4(4), 5320-5329. Doi: https://doi.org/10.1016/j.matpr.2017.05.042

Sitorus, F., \& Brito-Parada, P. R. (2020). A multiple criteria decision making method to weight the sustainability criteria of renewable energy technologies under uncertainty. Renewable and Sustainable Energy Reviews, 127, 109891. Doi: https://doi.org/10.1016/j.rser.2020.109891

Solangi, Y. A., Tan, Q., Mirjat, N. H., Valasai, G. D., Khan, M. W. A., Ikram, M. (2019). An Integrated DelphiAHP and Fuzzy TOPSIS Approach toward Ranking and Selection of Renewable Energy Resources in Pakistan. Processes, 7(2), 118. Doi: https://doi.org/10.3390/pr7020118

Stanujkic, D., Karabasevic, D., \& Zavadskas, E. K. (2015). A framework for the selection of a packaging design based on the SWARA method. Engineering Economics, 26(2), 181-187.

Şahin, U. (2016). Türkiye Elektrik Enerjisi Üretiminde Kullanılan Yenilenebilir Enerji Kaynaklarının Sürdürülebilirliğinin Değerlendirilmesinde Analitik Ağ Süreci (AAS) Yöntemi İle Fayda, Fırsat, Maliyet ve Risk (FFMR) Analizinin Kullanılması. Cumhuriyet Üniversitesi Fen-Edebiyat Fakültesi Fen Bilimleri Dergisi, 37, 180-188.

Şengül, Ü., Eren, M., Shiraz, S. E., Gezder, V., \& Şengül, A. B. (2015). Fuzzy TOPSIS method for ranking renewable energy supply systems in Turkey. Renewable energy, 75, 617-625.

Trappey, A.J., Trappey, C.V., Wang, D.Y., Ou, J.J., Li, S.J. (2015). An Integrated Self-Organizing Map and Analytic Hierarchy Process Modeling Approach for Evaluating Renewable Energy Polices, International Journal of Electronic Business Management, 13, 3-14.

Tsoutsos, T., Drandaki, M., Frantzeskaki, N., Iosifidis, E., \& Kiosses, I. (2009). Sustainable energy planning by using multi-criteria analysis application in the island of Crete. Energy policy, 37(5), 1587-1600.

Uygurtürk, H., Korkmaz, T. (2012). Finansal Performansın TOPSIS Çok Kriterli Karar Verme
Yöntemi ile Belirlenmesi: Ana metal sanayi işletmeleri üzerine bir uygulama, Eskişehir Osmangazi Üniversitesi İktisadi ve İdari Bilimler Dergisi, 7(2).

Vafaeipour, M., Hashemkhani Zolfani, S., Morshed Varzandeh, M.H., Derakhti, A., Keshavarz Eshkalag, M., 2014. Assessment of regions priority for implementation of solar projects in Iran: new application of a hybrid multi-criteria decision making approach. Energy Convers. Manag. 86, 653-663. Doi: https://doi.org/ $\underline{10.1016 / \text { i.enconman.2014.05.083 }}$

Volvačiovas, R. (2014). Visuomeninès paskirties pastatu atnaujinimo efektyvumo tyrimas ir daugiatikslis vertinimas (Doctoral dissertation, VGTU leidykla „Technika”).

Wang, T.C., Lee, H.D. (2009). Developing a Fuzzy TOPSIS Approach Based on Subjective Weights and Objective Weights, Expert Systems with Applications, 36(5), 8980-8985. Doi: https://doi.org/10.1016/j.eswa.2008.11.035

Wang, Y., Xu, L., \& Solangi, Y. A. (2020). Strategic renewable energy resources selection for Pakistan: Based on SWOT-Fuzzy AHP approach. Sustainable Cities and Society, 52, 101861. Doi: https://doi.org/10.1016/j.scs.2019.101861

Wiguna, K. A., Sarno, R., and Ariyani, N. F. (2016). Optimization solar farm site selection using multi-criteria decision making fuzzy ahp and promethee: case study in bali. In 2016 International Conference on Information \& Communication Technology and Systems (ICTS) (pp. 237-243). IEEE.

www.tuik.gov.tr/PreIstatistikTablo.do?istab_id=157 8, Erişim Tarihi: 15.05.2019, Konu: TÜİK Verileri.

Xue, D., Zhao, Q., and Guo, X. (2008). TOPSIS Method for Evaluation Customer Service Satisfaction to Fast Food İndustry. In Service Operations and Logistics, and Informatics, IEEE/SOLI 2008. IEEE International Conference on, 1, 920-925.

Yoon, K., Hwang, C.L., (1985). Manufacturing Plant Location Analysis by Multiple Attribute Decision Making: Part I-Single Plant Strategy, Int. J. Prod. Pres., 23(2), 345-359.

Yücenur, G. N., Çaylak, Ş., Gönül, G., \& Postalcıoğlu, M. (2020). An integrated solution with SWARA\&COPRAS methods in renewable energy production: City selection for biogas facility. 
Renewable Energy, 145, 2587-2597. Doi: https://doi.org/10.1016/i.renene.2019.08.011

Zheng, G., \& Wang, X. (2020). The comprehensive evaluation of renewable energy system schemes in tourist resorts based on VIKOR method. Energy, 193, $116676 . \quad$ Doi: https://doi.org/10.1016/j.energy.2019.116676

Zolfani, S. H., \& Banihashemi, S. S. A. (2014, May). Personnel selection based on a novel model of game theory and MCDM approaches. In Proc. of 8th International Scientific Conference" Business and Management (pp. 15-16). Doi: https://doi.org/10.3846/bm.2014.024

Zolfani, S. H., \& Saparauskas, J. (2013). New application of SWARA method in prioritizing sustainability assessment indicators of energy system. Engineering Economics, 24(5), 408-414. Doi: https://doi.org/10.5755/i01.ee.24.5.4526

Zolfani, S. H., Aghdaie, M. H., Derakhti, A., Zavadskas, E. K., \& Varzandeh, M. H. M. (2013). Decision making on business issues with foresight perspective; an application of new hybrid MCDM model in shopping mall locating. Expert Systems With Applications, 40(17), 7111-71. Doi: https://doi.org/10.1016/i.eswa.2013.06.040 